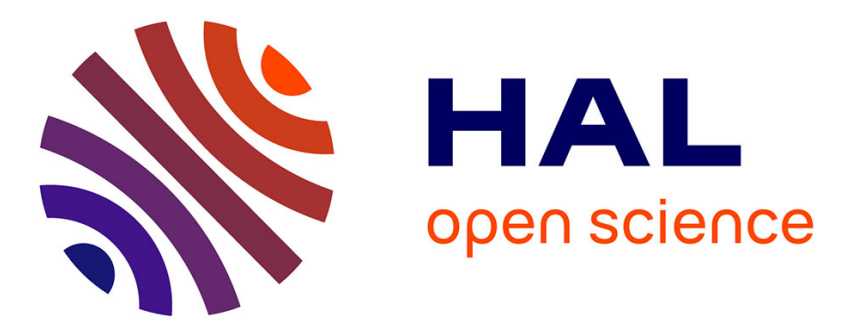

\title{
Dislocations and plasticity in semiconductors. II. The relation between dislocation dynamics and plastic deformation
}

\author{
J. Rabier, A. George
}

\section{- To cite this version:}

J. Rabier, A. George. Dislocations and plasticity in semiconductors. II. The relation between dislocation dynamics and plastic deformation. Revue de Physique Appliquée, 1987, 22 (11), pp.1327-1351. 10.1051/rphysap:0198700220110132700 . jpa-00245684

\section{HAL Id: jpa-00245684 https://hal.science/jpa-00245684}

Submitted on 1 Jan 1987

HAL is a multi-disciplinary open access archive for the deposit and dissemination of scientific research documents, whether they are published or not. The documents may come from teaching and research institutions in France or abroad, or from public or private research centers.
L'archive ouverte pluridisciplinaire HAL, est destinée au dépôt et à la diffusion de documents scientifiques de niveau recherche, publiés ou non, émanant des établissements d'enseignement et de recherche français ou étrangers, des laboratoires publics ou privés. 


\title{
REVUE DE PHYSIQUE APPLIQUÉE
}

Revue Phys. Appl. 22 (1987) 1327-1351

NOVEMBRE 1987, PAGE 1327

Classification

Physics Abstracts

$61.70-62.20 \mathrm{~F}-81.40 \mathrm{~L}$

\section{Dislocations and plasticity in semiconductors. II. The relation between dislocation dynamics and plastic deformation}

\author{
J. Rabier (*) and A. George (**)
}

(*) Laboratoire de Métallurgie Physique, Unité Associée au CNRS n 131, Faculté des Sciences, 40 avenue du Recteur Pineau 86022 Poitiers Cedex, France

(**) Laboratoire de Physique du Solide, Unité Associée au CNRS $n^{\circ} 155$, Ecole des Mines de Nancy, Institut National Polytechnique de Lorraine 54042 Nancy Cedex, France

(Reçu le 18 décembre 1986, révisé le 4 mai 1987, accepté le 10 juillet 1987)

\section{Overview article}

Résumé. - Dans cette seconde partie on examine le comportement mécanique des semi-conducteurs élémentaires (ESC) et composés III-V (CSC). La forte influence de la température sur la courbe contraintedéformation est rappelée et l'accent est mis sur le lien entre la limite élastique inférieure et la mobilité des dislocations aux températures moyennes. Dans $\mathrm{Si}$, une prédéformation bien choisie conduit à une situation très favorable où l'on peut mesurer à la fois la densité des dislocations mobiles et les contraintes locales et où les paramètres d'activation à la limite élastique inférieure sont ceux observés pour le glissement des dislocations. Dans les CSC, la très grande différence de mobilité des dislocations $\alpha$ et $\beta$ peut conduire à des effets de polarité et les paramètres d'activation obtenus sont assez différents de ceux déduits des mesures de vitesse. En général, le dopage affecte le comportement mécanique dans le sens où l'on s'y attend d'après les mesures de vitesses, mais des effets métallurgiques se produisent aux fortes concentrations si les atomes dopants sont mobiles à la température de déformation. A plus basse température, les SC peuvent être déformés sous fortes contraintes pourvu que la rupture fragile soit empêchée par une pression de confinement. Les techniques sont discutées et les résultats actuels suggèrent que les mécanismes élémentaires sont différents dans ce domaine, où — de plus - des effets d'environnement sont à prévoir. La dernière section traite de l'influence des impuretés non dopantes à l'aide des deux exemples les mieux connus : l'oxygène dans Si et l'indium dans GaAs.

\begin{abstract}
In this second part, the mechanical behaviour of elemental semiconductors (ESC) and III-V compounds (CSC) is briefly reviewed. The marked temperature dependence of the stress-strain curve is recalled first and some attention is paid to the correlation between the lower yield stress and dislocation dynamics at moderate temperatures. In $\mathrm{Si}$, some suitable pre-strain yields a very favourable situation where measurements of both mobile dislocation density and local stresses can be done and where activation parameters at the lower yield point fairly agree with those of dislocation glide. In CSC, polarity effects result from the very different mobility of $\alpha$ and $\beta$ dislocations and activation parameters apparently fail to reproduce those derived from velocity measurements. Generally, the mechanical behaviour is affected by doping in the sense expected from velocity measurements, but «metallurgical » effects appear at high concentrations if doping atoms are mobile at the deformation temperature. At lower temperatures, SC can be deformed under high stresses, if brittle fracture is prevented by a confining pressure. Experimental techniques are discussed and present results point to different rate controlling mechanisms in this range, where environment effects are in addition suspected. A last section deals with the influence of non-doping impurities, using the best known examples of oxygen in $\mathrm{Si}$ and indium in GaAs.
\end{abstract}

\section{Introduction.}

In the first part of this review [1], the structure and mobility of dislocations in crystals with diamond cubic and sphalerite structures have been considered. This second part deals with macroscopic plasticity and is chiefly concerned with the relation between dislocation dynamics and plastic deformation in elemental semiconductors (ESC) and III-V compounds (CSC).

As it has been recognized for a long time, mechanical properties of semiconductors strongly depend on temperature. For ease of presentation, 
the temperature range of interest can be roughly divided into three domains characterized by the experimental procedure to conduct compression tests at a fixed strain rate :

In the so-called high temperature range ( $T \geq 0.65 T_{\mathrm{m}}, T_{\mathrm{m}}$ melting temperature) initially dislocation-free crystals can be deformed in the usual range of strain rates $\left(\dot{\gamma} \sim 10^{-4} \mathrm{~s}^{-1}\right)$ without risk of brittle failure.

At medium temperature $\left(0.5 \leqq T \leqq 0.65 T_{\mathrm{m}}\right)$ a plastic deformation can be achieved in a standard Instron type machine only at low strain rates and after a suitable pre-strain at higher temperature has created a high starting dislocation density.

At low temperature, brittle fracture must be prevented by a confining hydrostatic pressure and a high starting dislocation density is also required to promote plastic deformation.

Of course, these rather ill-defined domains do not correspond necessarily to different rate controlling dislocation mechanisms. However, in view of the different techniques used, the comparison of results obtained in these domains may be different even if some overlap between them can be managed in most cases.

First a summary of general features of the stressstrain curve is given. The behaviour at large strains has been studied at high temperature (above $\left.0.7 T_{\mathrm{m}}\right)$, mainly in Si and Ge. Very little will be said about the recently discovered hardening stages IV and $\mathrm{V}$ since they have been described at length in a series of papers by Siethoff, Schroter et al. [2-5]. In most compounds, the high temperature range is difficult to study due to evaporation of the group $\mathrm{V}$ element and data are still very scarce, in spite of the increasing demand in order to solve the technological problem of how to reduce to zero the density of dislocations after crystal growth and device processing.

More detailed will be the yield region at medium temperature, i.e. in the range of dislocation velocity measurements. The yield behaviour of ESC has been explained by theoretical models, the best known of them being the model of Alexander and Haasen [6], whose basic assumptions and main predictions are summarized and compared to experiments. The determination of activation parameters, activation volume and activation Gibbs free energy, from stress relaxation tests is discussed. It will be seen, in the favourable case of silicon, that a quantitative estimation of the dislocation structure providing direct measurements of local stresses or mobile dislocation density, by TEM observations, is possible although in a rather limited range of experimental conditions.

The case of CSC will be treated separately since a qualitatively different behaviour is expected from the very large difference of mobility between $\alpha$ and $\beta$ or screw dislocations. The dislocation structure in deformed CSC is still poorly known. Qualitative results point to a striking resemblance to the case of bcc metals deformed at low temperature.

On the low temperature side, recent experiments by compression under confining pressure as well as extensive studies of the dislocation structure beneath micro-indentations near or at room temperature have provided a lot of data, which have to be compared with those obtained in conventional experiments at higher temperature and lower stress. A possible change in the rate controlling mechanism is especially looked for.

The influence of doping and neutral impurities on macroscopic deformation will also be described. Such data offer a further possibility to check in which way the dislocation mobility is reflected in the mechanical behaviour of single crystals.

Last, some suggestions for future work are proposed.

\section{General features of the stress-strain curve.}

Figure 1 shows typical stress-strain curves of semiconducting materials. The resolved shear stress $\tau$ is plotted versus the resolved shear strain $\gamma$ for deformation by uniaxial tension or compression of single crystals at « constant» strain rate:

The shape of the $\tau-\gamma$ curve with the classical three successive stages of hardening - easy glide, linear hardening, parabolic hardening - is the same as in fcc metals, except in the yield region. Such a similarity is not surprising since at large strains the flow stress and the work hardening rate are mainly determined by the geometry of interacting slip systems, which means that materials with the same Bravais lattice, i.e. the same slip systems, would exhibit basically the same behaviour.

There are however several differences which are more specific features of semiconductors. The main ones are reflected in the temperature dependence of the yield behaviour and of hardening stages.

1.1 TEMPERATURE AND STRAIN-RATE DEPENDENCES OF YIELD STRESSES. - The onset of plastic flow is typical of materials with a very small initial dislocation density resulting in a very large peak stress preceding the stage I of easy glide. The upper and lower yield stresses, $\tau_{\text {uy }}$ and $\tau_{\ell_{y}}$, are defined as the maximum and minimum stress respectively in the yield region. As the yield point corresponds to the smallest possible hardening this region of the stress-strain curve is the most closely related to isolated dislocation mobility. Special attention to it will be paid in a later section. Let us just define here the experimentally observed dependence of yield stresses on temperature and strain rates.

Figure 2 presents the results of Omri [7, 8], in FZ undoped $\mathrm{Si}$ at very low strain rates. In agreement with previous data, both $\tau_{\text {uy }}$ and $\tau_{\ell_{y}}$ are seen to 
a)

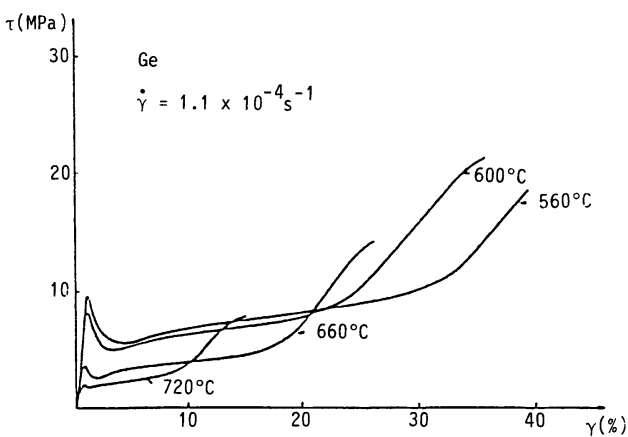

b)
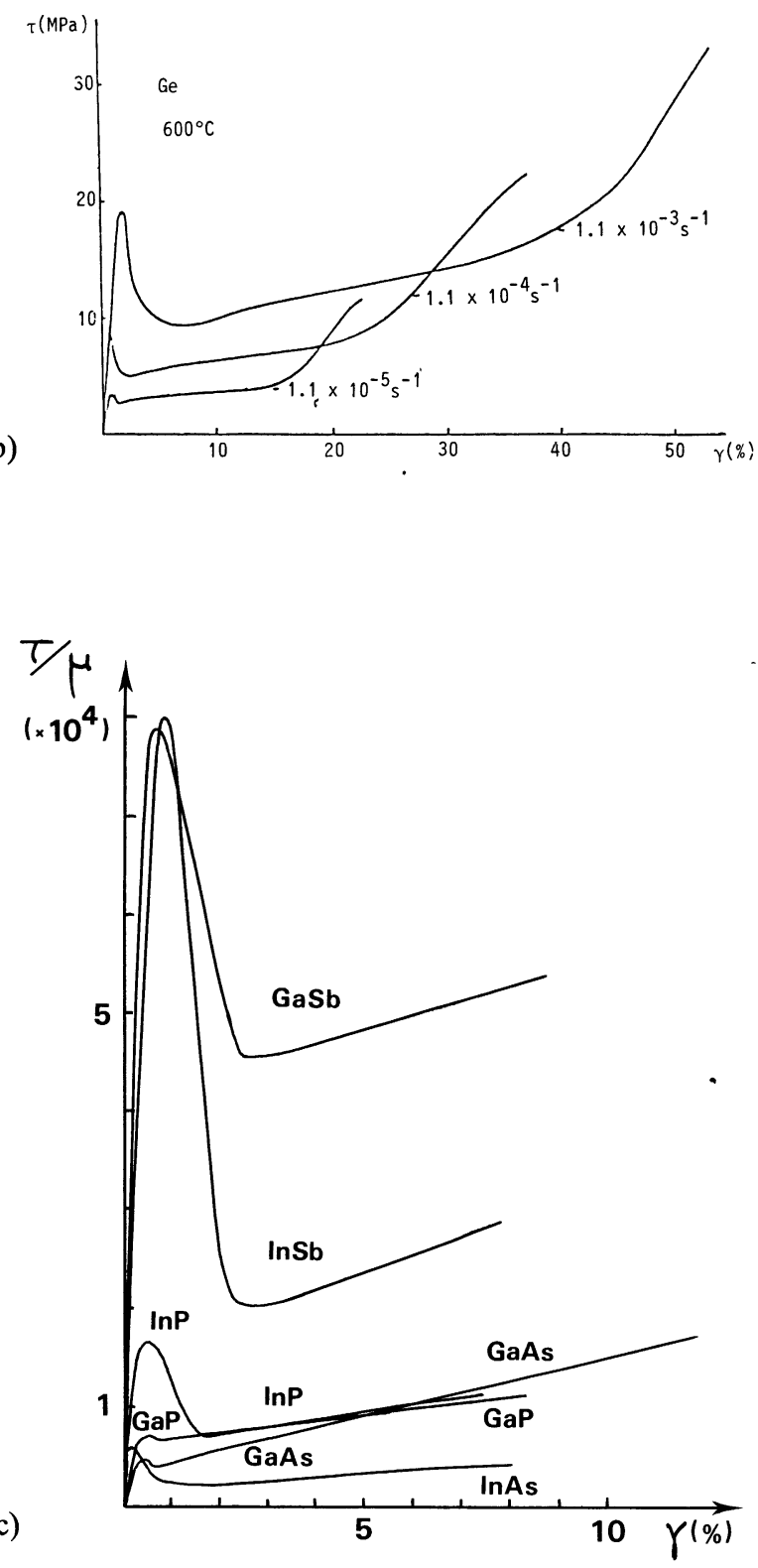

Fig. 1. - Resolved shear stress-shear strain curves of semiconductors : a) The effect of temperature on hardening stages in Ge, after [12]. b) The effect of strain rate on hardening stages in Ge, after [12]. c) Different behaviour of III-V compounds at the same homologous temperature $\left(0.65 T_{\mathrm{m}}\right)$ and $\dot{\gamma} \sim 3.6 \times 10^{-5} \mathrm{~s}^{-1}$, after [9].
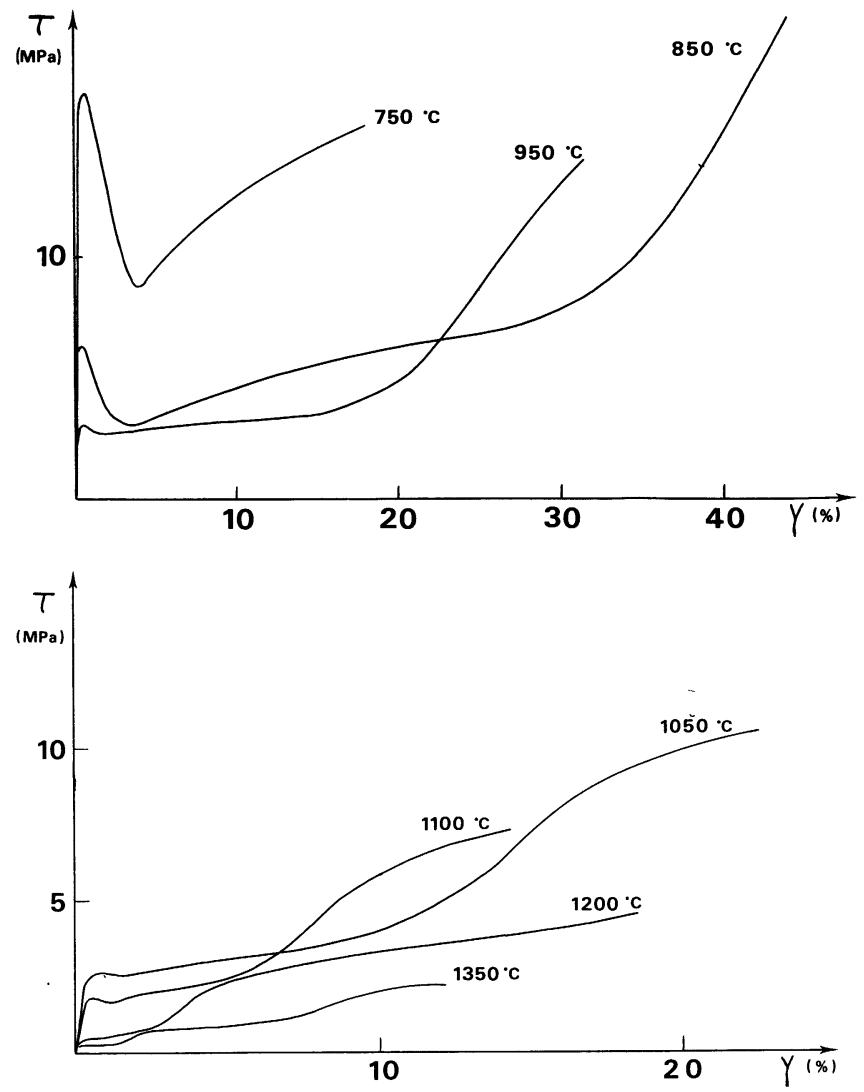

Fig. 2. - Resolved shear stress-shear strain curves of FZ silicon single crystals, after [7]. Note the five-stage curve at $1350{ }^{\circ} \mathrm{C}$.

steeply decrease with increasing temperature at $T \leq 0.8 T_{\mathrm{m}}$ (Fig. 3). In this temperature range a good phenomenological description is given by :

$$
\tau_{\mathrm{y}}=C \dot{\gamma}^{1 / n} \exp (U / k T)
$$

valid for the upper and lower yield stresses as well, with nearly the same values of $n$ and $U$ [6], despite

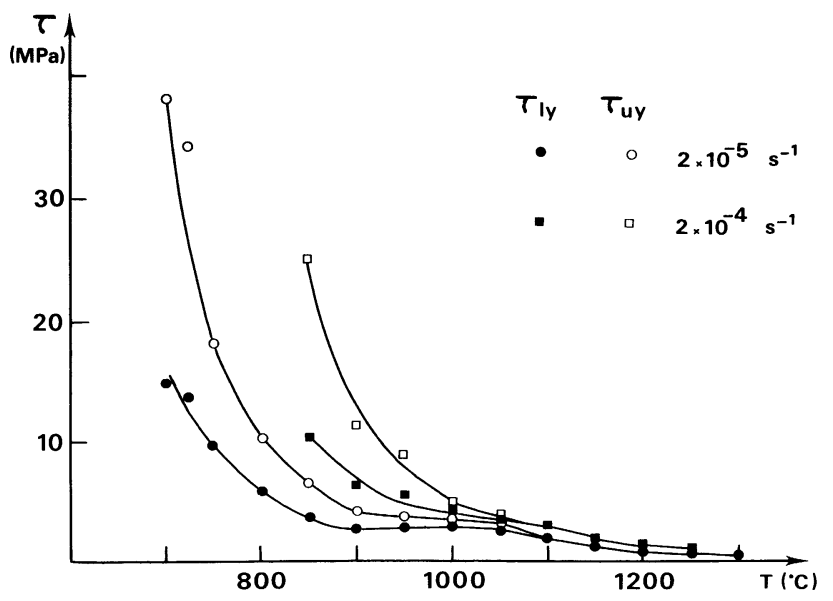

Fig. 3. - Temperature dependence of upper and lower yield stresses in initially dislocation-free FZ silicon at low strain rates, after [17]. 
the more rapid decrease of $\tau_{\text {uy }}$ with increasing $T$. The curves at $\dot{\gamma} \sim 2 \times 10^{-5} \mathrm{~s}^{-1}$ however prove that this temperature dependence is not obeyed up to the melting point : between $\sim 900^{\circ} \mathrm{C}$ and $\sim 1100^{\circ} \mathrm{C}$, $\tau_{\ell_{y}}$ is approximatively constant, while $\tau_{\text {uy }}$ still decreases, reducing the amplitude of the yield drop which vanishes out at $\sim 100^{\circ} \mathrm{C}$. At $T>1100^{\circ} \mathrm{C}$ $\tau_{y}$ is observed to decrease again. This defines a three-stage temperature dependence, like in fcc metals, with the differences that the low temperature domain is much more extended in covalent materials (up to $0.8 T_{\mathrm{m}}$ ), that the plateau may be very short and that the high temperature regime is confined to the immediate vicinity of the melting point $\left(\geq 0.9 T_{\mathrm{m}}\right)$. Omri observed that if the strain rate was increased the plateau disappeared, with a small transition between low and high temperature regimes marked by an inflection on the $\tau_{\mathrm{y}}(T)$ curve still appearing at $\dot{\gamma} \sim 2 \times 10^{-4} \mathrm{~s}^{-1}$. In most studies, higher strain rates were used and the plateau was not detected.

The dislocation velocity, of course, should directly influence the flow stress in the low temperature region, where the lattice friction can be overcome only by large applied stresses. In the plateau, the flow stress is expected to be primarily fixed by dislocation-dislocation interactions rather than by their intrinsic mobilities, which are very high due to the thermal activation of dislocation glide. As in metals, it is believed that at very high temperatures a continuous recovery of the dislocation structure (rapid annihilation of dipoles and multipoles) still decreases the flow stress.

The pronounced yield point is reduced or even suppressed if a sufficiently high dislocation density exists at the beginning or if the stress axis is along a symmetric orientation (multiple slip). The effect of a pre-strain is discussed in section 2.2. Recent results of compression along high symmetry orientation in Si were reported in $[10,11]$.

\subsection{TEMPERATURE DEPENDENCE OF HARDENING} STAGES. NEW HARDENING AND RECOVERY STAGES. - Like the yield region, later stages of the stress-strain curve strongly depend on temperature. The net effect is a reduction of both critical stresses and strains of any transition from one stage to the next one with increasing temperature. According to Sumino, the critical stresses obey similar phenomenological laws as yield stresses [12]. Consequently stage III appears at a rather small strain at high temperature and this fact allowed Siethoff and Schroter to find a second hardening stage stage IV - later followed by a second recovery stage with parabolic hardening - stage $\mathrm{V}$, in $\mathrm{Si}$ and $\mathrm{Ge}$ [25]. For a recent review of these studies of large strains the reader is referred to $[4,5]$. Computer fits to current models of dynamic recovery, now sup- plemented by High Voltage Electron Microscopy investigations [13] seem to point out that the crossslip mechanism as analysed by Escaig [14] is the relevant mechanism for the transition from stage IV to stage $\mathrm{V}$ at higher temperatures. The transition from stage II to stage III should be ascribed rather to recovery by dislocation climb. At lower temperature, where stages IV and V cannot be reached in compression because of the very large strains required, stage III would be, as in fcc metals, ascribed to cross-slip.

Stages IV and V have been also observed in metals [15], which confirms that the shape of the stress-strain curve is characteristic of the crystal structure rather than of the type of atomic bonding.

As pointed out by Siethoff himself [16], a good fit to any model is not a definite proof that the rate controlling mechanism has been identified and it would be very useful to investigate in more detail the predictions of the model. In Escaig's model of crossslip for example, the orientation dependence or the tension/compression asymmetry should be experimentally checked. A recent attempt to determine the activation parameters of cross-slip in Si by means of the two-step deformation technique used in $\mathrm{Cu}$ and $\mathrm{Al}[17,18]$ was not successful [19]. Cross-slip of isolated dislocations in $\mathrm{Si}$ and $\mathrm{Ge}$ was often reported $[20,21]$ and quantitatively studied by Möller [22, 23] but these observations refer only to cross-slip at a free surface, where a constriction of the stacking fault ribbon can spontaneously form because of image forces [24]. Cross-slip in the bulk should be different, even if occasional constrictions may be formed at trees.

\section{Correlation between the lower yield stress and dislocation dynamics in ESC.}

The plastic strain rate $\dot{\gamma}$ is related to the dislocation velocity $v$ through the Orowan equation :

$$
\dot{\gamma}=\rho_{\mathrm{m}} b v
$$

where $\rho_{\mathrm{m}}$ is the mobile dislocation density and $b$ the magnitude of the Burgers vector. There are many possibilities to combine $\rho_{\mathrm{m}}$ and $v$ to give the imposed $\dot{\gamma}$. The purpose of a model is to determine which combination is actually realized. Needless to say, $\rho_{\mathrm{m}}$ and $v$ values entering in (2) have to be averaged over the specimen gauge length and this is a further difficulty.

The yield behaviour of semiconductors is qualitatively well understood.

(i) A good phenomenological description of the stress and temperature dependence of dislocation velocity is available from velocity measurements.

(ii) There is plenty of evidence that the initial peak stress is due to dislocation multiplication (an 
effect once proposed by Johnston and Gilman to account for their results in $\mathrm{LiF}$ [25]). The very few if non zero - grown-in dislocations are totally unable to achieve the imposed strain rate and an essential ingredient of any model is a multiplication law for moving dislocations. As dislocations multiply they become able to ensure the strain rate at a reduced velocity, that is under a lower stress, which explains the softening beyond the upper yield point.

(iii) The minimum flow stress, $\tau_{\ell_{y}}$, results from the increasing importance of dislocation-dislocation interactions, which on average reduce the dislocation velocity. It is equivalent to say that dislocations experience an effective shear stress $\tau_{\text {eff }}$ smaller than the applied stress, $\tau$. A theory of the effective stress is a further ingredient necessary to any model.

2.1 The MOdel of HAASEN [6]. - The hypothesis underlying the model are referred to as $(\mathrm{H} . i)$ in what follows. Haasen assumes that the deformation is homogeneous (H.0) and that the mobile dislocation density $\rho_{\mathrm{m}}$ is equal to the total one $\rho$ (H.1). The dislocation velocity is described by :

$$
v=v_{0}\left(\tau_{\text {eff }} / \tau_{0}\right)^{m} \exp (-Q / k T)=B(T) \tau_{\text {eff }}^{m}
$$

with a stress independent $Q$ (H.2). The internal stress $\tau_{i}$ is due to long range stresses of like dislocations and the effective stress (H.3) is simply taken as :

$$
\tau_{\text {eff }}=\tau-\tau_{\mathrm{i}}=\tau-A \sqrt{\rho}(A \cong \mu b / 2 \pi(1-\nu)) .
$$

It is experimentally clear that fresh dislocations soon result no longer from fixed sources but are multiplied by moving dislocations themselves. The assumed multiplication law (H.4) is :

$$
\mathrm{d} \rho / \mathrm{d} t=K \rho v \tau_{\mathrm{eff}}^{\alpha}
$$

with $\alpha=1$ in the original model.

The total strain rate consists of an elastic and a plastic component :

$$
\dot{\gamma}=\dot{\tau} / \mu_{\text {eff }}+\rho b v=\text { Const } .
$$

where $\mu_{\text {eff }}$ is the effective shear modulus of the sample plus machine assembly. Both the upper and lower yield points are characterized by $(\partial \tau / \partial \gamma)_{\dot{\gamma}}=0$. The reader is referred to [6] for a discussion of the upper yield point. In the lower yield region, Haasen neglects the first term of equation (6) and $\tau_{l_{y}}$ is determined by the system of equations :

$$
\begin{aligned}
& \mathrm{d} \gamma / \mathrm{d} t=b \rho B(T)(\tau-A \sqrt{\rho})^{m} \\
& \mathrm{~d} \rho / \mathrm{d} t=K \rho B(T)(\tau-A \sqrt{\rho})^{m+1} .
\end{aligned}
$$

As $\rho$ is an increasing function of the strain, the condition for the lower yield point is equivalent to :

$$
(\partial \tau / \partial \rho)_{\dot{\gamma}}=0 \text {. }
$$

The observed temperature dependence of $\tau_{\ell y}$ is well predicted with

$$
\tau_{\ell_{y}}=C \dot{\gamma}^{1 / m+2} \exp [+Q /(m+2) k T] .
$$

Important predictions of the model are :

$$
\rho_{\ell y}=(2 / 2+m)^{2} \tau_{\ell y}^{2} / A^{2}
$$

and

$$
\tau_{\text {eff, } \ell_{y}}=\tau_{\ell_{y}}[m /(2+m)]
$$

that is, with $1<m<2$, the effective stress is between $1 / 3$ and $1 / 2$ of the applied stress at the lower yield point.

Contrarily to $\tau_{\text {uy }}, \tau_{\ell_{y}}$ should not depend on the initial dislocation density.

According to Haasen, at the lower yield point, a steady state is reached for both the dislocation density and the effective stress.

Remarks. - (i) Assumption H.1 is not as crude as it seems : the multiplication law was checked by etch pit counts and, at this early stage of the deformation since most of dislocations belong to the primary slip plane, reactions form dipoles or multipoles which do not show up in etch patterns, so that $\rho$ measured may be closer to $\rho_{\mathrm{m}}$ than to $\rho$ total.

(ii) The multiplication law should deserve more attention. Whereas the statement $\mathrm{d} \rho / \mathrm{d} t \cong K^{\prime} \rho$ may be intuitive, the origin of a linear dependence of the multiplication factor $K^{\prime}$ on $v$ is not evident. Also the most probable muliplication mechanism is usually assumed to involve double cross-slip which would require consideration of the shear stress in the cross slip plane. It would be interesting to look for a possible orientation dependence on the $\tau$ - $\gamma$ curve in the yield region. In nearly all studies the stress axis - for single glide geometry - was chosen along the same $\langle 123\rangle$ orientation, which is not convenient to explore such an effect since there is no shear stress applied on the cross-slip plane.

(iii) The case of an initially zero dislocation density, realistic in such materials, cannot be treated by the model. In this case of course the upper yield stress should critically depend on available dislocation sources such as damage of free surfaces and grown-in micro defects.

(iv) In spite of remark (i), Yonenaga and Sumino [26] convincingly proved that forest dislocations can play a non negligible role in the yield region and may explain the weak but real dependence of $\tau_{\ell_{y}}$ on the initial dislocation density $\rho_{0}$ : the lower $\rho_{0}$, the higher $\tau_{\text {uy }}$ peak stress, which favours the activation of secondary slip systems. Secondary dislocations in 
turn increase the amount of internal stress at $\tau_{\ell \mathrm{y}}$

(v) It has been long recognized [27] that the deformation is not homogeneous in the yield region. Takeuchi [28, 29] considered the yield point as resulting from the progressive filling of the sample gauge length by deformation bands. Using the same description of $v(\tau, T)$ and $\tau_{\mathrm{i}}(\rho)$, he introduced a new and important hypothesis : within a deformation band the mobile dislocation density at a given stress is such that the plastic strain rate becomes maximum :

$$
\left(\partial \dot{\gamma}_{\mathrm{p}} / \partial \rho_{\mathrm{m}}\right)_{\tau}=0
$$

or equivalently the applied stress takes a minimum value to give a constant strain rate :

$$
\left(\partial \tau / \partial \rho_{\mathrm{m}}\right)_{\dot{\gamma}}=0
$$

(vi) This hypothesis of a steady state was also applied by Sumino and coworkers to the analysis of the flow stress in $\mathrm{Si}$ and Ge. Suezawa et al. [30] first pointed out that the condition derived by Haasen for the lower yield point is not exact if $\dot{\gamma}_{p}$ is not neglected in a strain range through the yield point. The correction however is rather small.

The most important proposal of these authors is that a steady state of deformation is reached some strain after the lower yield point only and is maintained during later stages of the $\tau-\gamma$ curve : on average both the mobile dislocation density and the effective stress (i.e. the average dislocation velocity) take constant and optimal values. This important statement relies however on a technique of measuring the effective stress by strain rate jumps, which, in our opinion, cannot give very accurate results : these authors assumed that the «immediate » drop of the flow stress, which follows the jump, directly reflects the change of dislocation velocity, without any change of $\rho_{\mathrm{m}}$. According to the experience of one of us, other effects, like pen inertia, make the flow stress drop difficult to measure, resulting in a rather wide uncertainty in the derivation of $\tau_{\text {eff }}$. For the practical difficulties of using strain rate jumps see for example Basinski and Basinski [31].

On the other hand, the hardening rate is not explained in the model but simply described by the phenomenological relation :

$$
\Delta \tau_{\mathrm{i}} \alpha \Delta \gamma
$$

(vii) The very good agreement between experiments and the above mentioned models might be less convincing than it seems since, in all cases, velocity data had to be extrapolated to higher temperatures and also to lower stresses to be compared with macroscopic data. According to the characteristics of dislocation velocities summarized in the first part of this paper, such an extrapolation is highly questionable.

2.2 AN EXPERIMENTAL RE-INVESTIGATION OF THE LOWER YIELD POINT IN SILICON. - In this section is summarized a recent study done by Omri [7], Oueldennaoua [32] and Allem [33] in Nancy with a somewhat different goal. The basic idea was to measure separately the terms of Orowan's equation and to check the consistency of these data. The work has been done in several steps.

(i) Measure yield stresses under such deformation conditions that any extrapolation of velocity measurements can be avoided.

(ii) Decrease as much as possible the importance of dislocation multiplication, in order to make the influence of dislocation velocity on the flow stress more straightforward. •

(iii) In the course of compression experiments, use the standard techniques of stress relaxation to derive apparent activation parameters to be compared to those characterizing the glide of single dislocations.

(iv) Estimate quantitatively the dislocation structure, taking advantage of the unique possibility to freeze-in under stress any high temperature configuration.

2.2.1 The choice of deformation conditions. - The simplest situation to relate dislocation dynamics to the flow stress would be to have at one's disposal a fixed dislocation density, sufficiently high to assure the imposed strain rate at low stress and sufficiently low so that any dislocation interactions could be neglected. This ideal cannot be achieved: if the density of dislocations is low enough for hardening to be negligible, dislocation multiplication cannot be prevented. It is however possible to minimize it by a suitable pre-strain.

The best pre-strain conditions are not obviously defined. The major effect of prestraining is to strongly reduce the yield drop by decreasing $\tau_{\text {uy }}$. The yield drop can even be totally suppressed but this would lead to a higher yield stress compared to the $\tau_{\ell_{\mathrm{y}}}$ value of less - or non - pre-strained samples. Under given $\dot{\gamma}, T$ conditions, one pre-strain gives the lowest $\tau_{\ell_{\mathrm{y}}}$ but this optimized pre-strain is not the same for a wide range of $\dot{\gamma}$ and $T$ conditions. Therefore one has to decide between standard prestrain given to all samples and optimized pre-strain defined for each $\dot{\gamma}, T$ conditions.

In the work of Omri [7], all samples received a standard pre-strain of $\gamma \sim 6 \times 10^{-2}$ (end of stage I) at $1050{ }^{\circ} \mathrm{C}, \dot{\gamma}=2 \times 10^{-5} \mathrm{~s}^{-1}$ i.e. in the athermal range of $\tau_{\ell_{\mathrm{y}}}$. This treatment reduced $\tau_{\ell_{\mathrm{y}}}$ at $T<800{ }^{\circ} \mathrm{C}, \quad \dot{\gamma}=2 \times 10^{-5} \mathrm{~s}^{-1}, \quad T<900{ }^{\circ} \mathrm{C}, \quad \dot{\gamma}=$ $2 \times 10^{-4} \mathrm{~s}^{-1}$. Pre-strained FZ Si could thus be 
deformed at three strain-rates, in the range $550{ }^{\circ} \mathrm{C}$ $600{ }^{\circ} \mathrm{C}$. As seen in figure 3 , yield stresses fall in the central range of dislocation mobility measurements (see [1]).

2.2.2 The determination of activation parameters. From the set of $\tau_{\ell_{y}}$ values measured at different temperatures and strain rates, a straightforward check of the temperature dependence can be done. As expected from other studies and models (Eq. (6)).

$$
\dot{\gamma}=\mathrm{C} \tau_{\ell \mathrm{y}}^{1 / n} \exp (-Q / k T)
$$

interpolating the different temperatures corresponding to given $\dot{\gamma}$ values at a constant $\tau_{\ell_{\mathrm{y}}}$ level, $Q$ is derived to be slightly higher than $2 \mathrm{eV}$, in fair agreement with the activation energy of dislocation velocity (as predicted by Haasen but without any need to include the strain rate sensitivity in the picture). This check requires experiments performed at different strain-rates.

The activation energy can also be derived following the classical formalism introduced by Schoeck [34] (see for example [35]), from the very general assumption that :

$$
\dot{\gamma}=\dot{\gamma}_{0} \exp (-\Delta G / k T)
$$

and using the experimentally determined activation volume, $V$

$$
V=k T(\partial \operatorname{Ln} \dot{\gamma} / \partial \tau)_{T} .
$$

Assuming that the dislocation structure does not vary much at the lower yield point under the investigated $\dot{\gamma}, T$ conditions (in pre-strained samples !) one is allowed to identify :

$$
\left(\frac{\partial \Delta G}{\partial \tau}\right)_{T, s s}=-V
$$

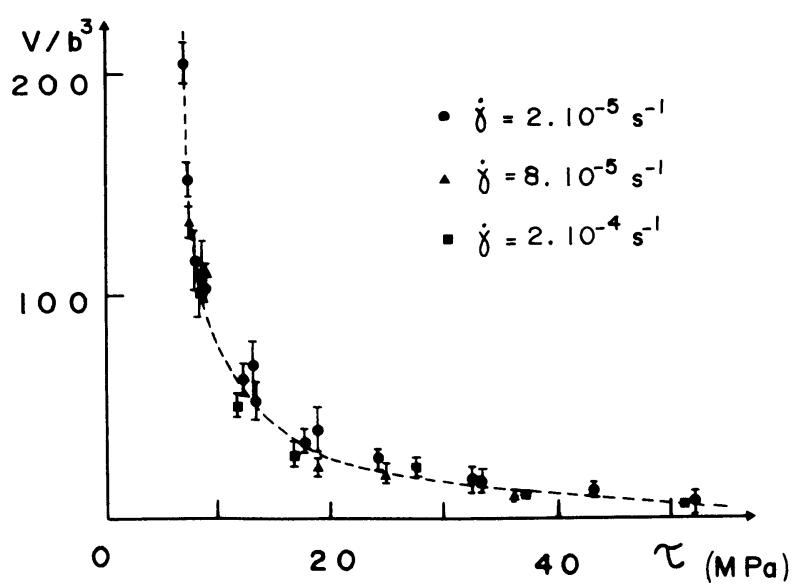

Fig. 4. - Apparent activation volumes at the lower yield point in $\mathrm{FZ}$ silicon single crystals (after a standard prestrain of $\left.\gamma \sim 6 \times 10^{-2}, \dot{\gamma}=2 \times 10^{-5} \mathrm{~s}^{-1}, T=1050^{\circ} \mathrm{C}\right)$, after [7]. where the subscript ss implies that the partial derivative is taken at a constant dislocation structure, and to calculate $\Delta G$ by a direct integration. One has to take into account the variation of entropy, which stems from the temperature dependence of the elastic modulus [36], a small correction in the present case, since elastic constants in covalent crystals are weaker functions of temperature than in metals [37]. As a result the Gibbs free energy of activation, $\Delta G$, is not very different (by $\sim 10 \%$ at most) from the activation enthalpy, $\Delta H$. The integration technique would require the knowledge of the yield stress at $0 \mathrm{~K}$, a datum impossible to measure. This is overcome by noting that :

$$
\Delta G(\tau, T)=k T \operatorname{Ln} \dot{\gamma}_{0} / \dot{\gamma}=\alpha k T
$$

(consistent with the hypothesis of a constant dislocation structure) and calculating $\alpha$ by integration in limited ranges of temperature. A constant value (at a given $\dot{\gamma}$ ) is obtained and $\Delta G$ values range from $1.8 \mathrm{eV}$ to $2.3 \mathrm{eV}$ in the stress range 45 to $3 \mathrm{MPa}\left({ }^{1}\right)$ in rather good agreement once again with $60^{\circ}$ dislocation velocity measurements though the stress dependence of $\Delta G$ is somewhat smaller in the latter (direct velocity measurements give $Q$, i.e. $\Delta H$, $\sim 10 \%$ higher than corresponding $\Delta G$ values).

$\Delta H$ was also determined from the formula :

$$
\Delta H=-T V\left(\partial \tau_{\ell y} / \partial T\right)_{\dot{\gamma}, s s}
$$

again values ranging slightly above $2 \mathrm{eV}$ were obtained.

It is important to remark that these determinations are not very accurate. The main source of error lies in the determination of the apparent activation volume. As explained elsewhere [7], measuring small activation volumes (as expected for a lattice friction mechanism) at rather high temperature by the conventional technique of Guiu and Pratt [38] can be totally misleading. A full check of the consistency of all parameters including the elastic behaviour of the machine-plus-sample assembly is needed to get reliable values of $V$. Even with these cautions the error bar should in most cases exceed $10 \%$, which scatter is reflected in $\Delta G$ because of the limited number of available data points. Obviously, an error of $10 \%$ on $\Delta G \sim 2 \mathrm{eV}$ would cause such important changes in the prefactor so that no conclusions about the possible trends of the latter are possible. The only possible conclusion that can be drawn from the overall agreement between $\Delta G$ derived by integration of $V$ and the activation energy for dislocation velocity may be that the stress dependence of the latter mainly stems from the

(1) These values are for applied stress at l.y.p. corrected by subtracting $2.5 \mathrm{MPa}$, the yield stress in the athermal regime (plateau) 
stress dependence of the activation energy, a fact which is obscured by the general use of the empirical stress exponent in the prefactor. (Remark: the activation free enthalpy at zero stress is in principle attained at the transition temperature to the athermal regime, $T_{c}$. As this quantity is not measured very accurately the extrapolation to $\Delta G_{0}$ is however rather inaccurate).

The assumption of a negligible change of the dislocation structure strictly contradicts the dependence of $\rho_{\mathrm{m}}$ upon deformation conditions predicted by the model of Haasen. It is believed that pre-strain reduced the need for dislocation multiplication. A check of that point was attempted by a TEM investigation of the dislocation structure at the lower yield point, which is reported on now.

2.2.3 TEM investigations at the lower yield point. All samples were cooled down in the stress applied state.

Figure 5 shows a typical dislocation structure at the lower yield point at $T=750^{\circ} \mathrm{C}$, $\dot{\gamma}=2 \times 10^{-5} \mathrm{~s}^{-1}, \tau_{\ell y} \sim 7 \mathrm{MPa}$. As known for a long time [6], such a configuration is very similar to any easy glide dislocation arrangement in fcc metals near room temperature. Most dislocations are primary

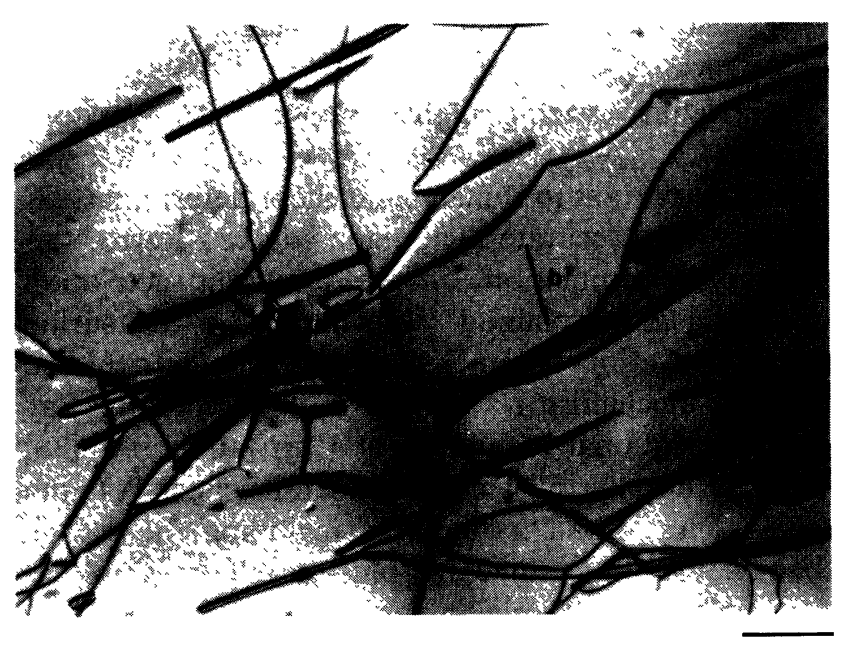

Fig. 5. - Typical dislocation structure observed by TEM in silicon after deformation at the lower yield point at $T \geqslant 700{ }^{\circ} \mathrm{C}, \dot{\gamma}=2 \times 10^{-5} \mathrm{~s}^{-1}, \tau_{\ell_{y}} \leqslant 10 \mathrm{MPa}$, after [32] : bundles of «edge type » dipoles, without precise crystallographic orientations (b, primary Burgers vector, marker : $1 \mu \mathrm{m})$.

ones and are involved in dipoles or more complex tangles with a strong edge character but no precise crystallographic orientations. A few dislocations are seen to bow out of tangles. This configuration is very close to that attained after the pre-straining treatment.
Quite different appears the dislocation structure at the lower yield point at lower temperatures. Figure 6 gives a typical view at $T=550^{\circ} \mathrm{C}$, $\dot{\gamma}=2 \times 10^{-5} \mathrm{~s}^{-1}, \tau_{\ell_{\mathrm{y}}}=41 \mathrm{MPa}$. Dislocations are distributed very homogeneously, they consist of pure screw or $60^{\circ}$ dislocations connected by curved bends. Few dipoles are visible. At $\dot{\gamma}=2 \times 10^{-5} \mathrm{~s}^{-1}$ the transition between crystallographic and « random » orientations takes place at $\leqslant 650{ }^{\circ} \mathrm{C}$, a rather low temperature, and at $\tau \geq 13 \mathrm{MPa}$.

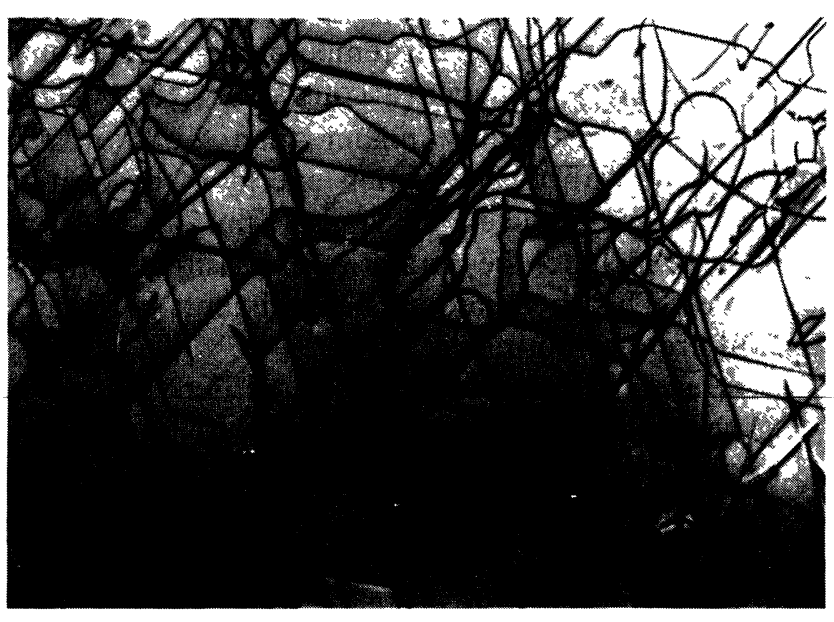

Fig. 6. - Typical dislocation stucture observed by TEM in silicon after deformation at the lower yield point at $550{ }^{\circ} \mathrm{C}, \dot{\gamma}=2 \times 10^{-5} \mathrm{~s}^{-1}, \tau_{\ell \mathrm{y}}=41 \mathrm{MPa}$, after [32] : homogeneous distribution of screw and $60^{\circ}$ dislocations (b, primary Burgers vector, marker : $1 \mu \mathrm{m}$ ).

The low temperature configuration is highly favourable for a quantitative estimation of microscopic parameters that enter in models. As discussed in detail by Gottschalk [39], the radius of curvature of dislocation bends gives a rather accurate measure of the local shear stress effectively exerted on the dislocation line, provided that the line tension is properly taken into account. (Difficulties occur at very high stresses when the radius of curvature is of the same order of magnitude as the dissociation width. In such cases a more elaborate calculation has to be done, but the stress range of interest in our experiments is free of these complications.)

With a sufficiently large number of measurements there is a hope to estimate not only the average value of the local stress but also the amplitude of stress fluctuations, a quantity whose knowledge is critical for an estimation of the effective stress. The mobile dislocation density also is readily measured, one simply has not to count the few dipoles or multipoles. (An underestimation of $\rho_{\mathrm{m}}$ can however result from overlapping images at high densities $\sim 10^{9} \mathrm{~cm} \cdot \mathrm{cm}^{-3}$ ). 
At higher temperatures and lower applied stresses the situation is not so convenient. Both mobile dislocation density and local stress are practically impossible to measure. The radius of curvature of a bowing dislocation pinned at two points would give a correct local stress value when the dislocation is actually pinned. If, on the contrary, it was overcoming the pinning point at the time the deformation was stopped, the instantaneous curvature that has been frozen-in has nothing to do with the local stress [40]. Also, at low stresses, an apparently free dislocation line may as well have been actually trapped in a dipole since the trapping distance between dislocations of opposite signs is now larger than the foil thickness.

After pre-strain the total dislocation density $\rho_{\mathrm{T}}$ was about $3 \times 10^{8} \mathrm{~cm} . \mathrm{cm}^{-3}, \rho_{\mathrm{m}}$ being certainly less than $4 \times 10^{7} \mathrm{~cm} \cdot \mathrm{cm}^{-3}$. The variation of $\rho_{\mathrm{m}}$ and $\rho_{\mathrm{T}}$ with straining conditions are given in figure 7 . The total dislocation density varies very weakly upon stress conditions, the dependence of $\rho_{\mathrm{m}}$ being stronger $\rho \alpha \tau^{\lambda}$ with $1<\lambda<2$ between $650{ }^{\circ} \mathrm{C}$ $(\tau \sim 13 \mathrm{MPa})$ and $550{ }^{\circ} \mathrm{C}(\tau \sim 41 \mathrm{MPa})$. In this stress range, it can be shown that the contribution of the prefactor (due to $\rho(\tau)$ ) to the apparent activation volume can be neglected.

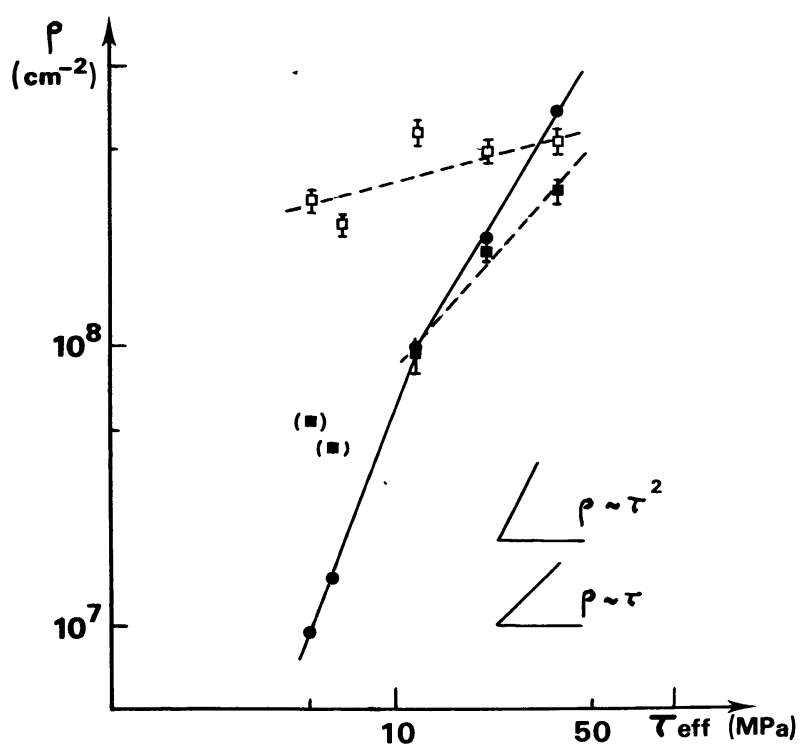

Fig. 7. - Dislocation density at the lower yield point as a function of the effective stress in FZ silicon deformed at $\dot{\gamma}=2 \times 10^{-5} \mathrm{~s}^{-1}$ after standard pre-strain, after [32]. $\square$, total measured dislocation density $; \boldsymbol{\square}$, measured mobile dislocation density; $\bullet$, calculated mobile dislocation density, see text for details.

Histograms of local stresses $\tau_{\text {loc }}$ exhibit, in the whole temperature range, a marked maximum at an average stress which was equal to the applied $\tau_{\ell y}$ within the experimental scatter. The standard deviation $\Delta \tau$ from this average value was found to be a slightly varying fraction of the applied stress, ranging from $\sim 0.25 \bar{\tau}_{\text {loc }}$ at $40 \mathrm{MPa}$ to $\sim 0.4 \bar{\tau}_{\text {loc }}$ at $6 \mathrm{MPa}$.

Fluctuations of the stress acting on dislocations result in an effective stress that was calculated as follows. The stress field was described by :

$$
\tau=\bar{\tau}_{\text {loc }}+\delta \tau \sin k x
$$

and $\bar{v}$, the average velocity of a dislocation in that stress field, was calculated following Alexander and Haasen [6], using the known stress dependence of the dislocation velocity, written here for convenience :

$$
v=v_{0}(T)\left(\tau / \tau_{0}\right)^{m}=B(T) \tau^{m} \text { with } 1<m<2
$$

This gives

$$
\bar{v}=B(T) \tau_{l_{\mathrm{y}}}^{1-m}\left(\tau_{\ell_{\mathrm{y}}}^{2}-\delta \tau^{2}\right)^{m-1 / 2}=B(T) \tau_{\mathrm{eff}}^{m} .
$$

The difficulty is to estimate the fluctuation of $\tau_{\text {loc }}$. With $\delta \tau$ equal to the standard deviation in the histograms $\Delta \tau=0.4 \tau_{\ell_{y}}$, equations $(17,18)$ give :

$$
\tau_{\text {eff }}=0.9 \tau_{\ell y} .
$$

(Taking $\delta \tau=2 \Delta \tau=0.8 \tau_{\ell \mathrm{y}}$ would lead to $\tau_{\text {eff }}=$ $0.55 \tau_{\ell_{y}}$.)

$\bar{v}$ and $\tau_{\text {eff }}$ being determined, it was possible to calculate the mobile dislocation density required to achieve the imposed strain rate, according to Orowan's equation. A fair agreement is found between calculated and measured $\rho_{\mathrm{m}}$, assuming $\tau_{\text {eff }} \cong 0.9 \tau_{\ell_{y}}$, at $\tau_{\ell_{\mathrm{y}}} \geq 13 \mathrm{MPa}$, i.e. as long as dislocations lie along $\langle 110\rangle$ orientations. (In this range, $\tau_{\text {eff }}=0.55 \tau_{\ell_{\mathrm{y}}}$ would lead to calculated $\rho_{\mathrm{m}}$ much larger than the measured total dislocation density. At lower stress, not surprisingly the tentatively measured $\tau_{\ell_{y}}$ were clearly overestimated (Fig. 7).

At $\tau \geq 13 \mathrm{MPa}$ we obtained a very satisfying consistency for all measurements, with evidence of an effective stress close to the applied one and the possibility to neglect the stress dependence of $\rho_{\mathrm{m}}$ in the derivation of the Gibbs free energy of activation.

It must be stressed that $\tau_{\text {eff }} \sim \tau_{\ell_{y}}$ strongly disagrees with the predictions of Haasen's model (Eq. (8)). Consistently the measured $\rho_{\mathrm{m}}$ in our experiments is smaller than predicted by (7). It may be suggested that at low temperature the multiplication of dislocations may be largely inhibited by the intrinsic difficulty of cross-slipping, a mechanism usually involved in multiplication according to the phenomenological law (4). In fact, Oueldennaoua noticed that below $\sim 600^{\circ} \mathrm{C}$ screw dislocations were present at the lower yield point in about equal proportion as each of the two types of $60^{\circ}$, whilst 
above $\sim 600^{\circ} \mathrm{C}$ the proportion of screws rapidly decreased, even when the dislocations were still oriented preferentially along the Peierls valleys.

A strong limitation of this time-consuming experimental work is that all measurements required are possible only in such narrow a range of $T, \tau$ conditions that no safe extrapolation nor the determination of a phenomenological dependence can be done.

A continuation of this work, presently under way in Nancy, is however offered by the very smooth transition from the upper to the lower yield point at $\sim 550^{\circ} \mathrm{C}, \dot{\gamma} \sim 2 \times 10^{-5} \mathrm{~s}^{-1}$. This large yield strain allows one to cool down under load samples deformed at intermediate points between u.y.p. and 1.y.p. in order to investigate by TEM the progressive transition from the high temperature low stress dislocation structure inherited from pre-straining towards the very different configurations observed at the lower yield points (Fig. 8). Of great interest would be to "measure " the scale of plastic inhomogeneities in that range but this is probably beyond the possibility of our technique.

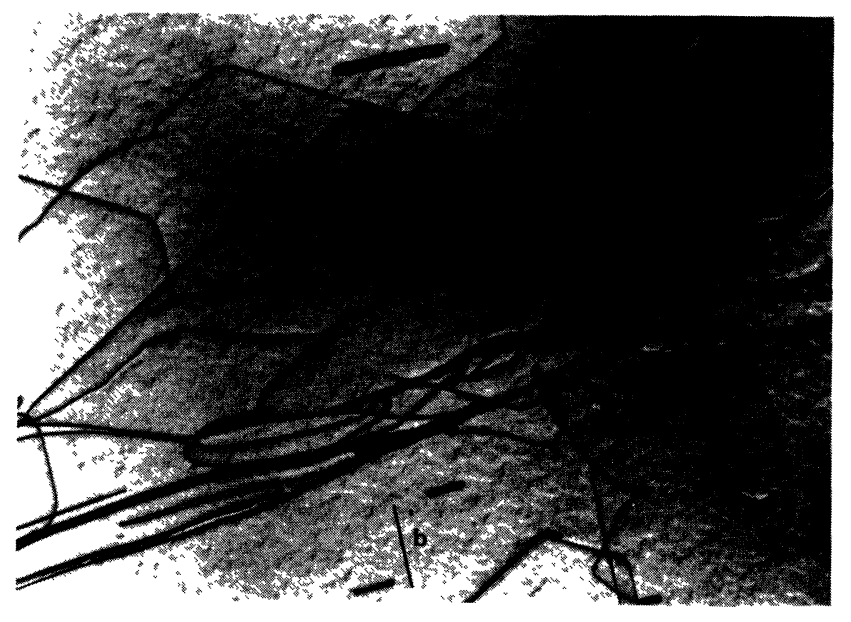

Fig. 8. - Transition between the entangled substructure inherited from high temperature pre-strain and the low temperature substructure (crystallographic orientations) in silicon deformed at $T=550{ }^{\circ} \mathrm{C}, \quad \dot{\gamma}=2 \times 10^{-5} \mathrm{~s}^{-1}$, $\tau=45 \mathrm{MPa} \cong 2 / 3 \tau_{\text {uy }}$, after [33]. (b, primary Burgers vector, marker : $1 \mu \mathrm{m}$ ).

3. Plasticity of III-V compounds at medium and high temperatures.

3.1 POLARITY EFFECTS. - In III-V compounds a permanent challenge is to evaluate the possible consequences of the large difference in $\alpha$ and $\beta$ mobilities on the mechanical properties and conversely to tailor special deformation conditions to create simple configurations involving one type of majority dislocations only, with the purpose to study electrical properties of these dislocations. As a matter of fact, several « polarity » effects have been observed, the interpretations of which are usually not straightforward.

The earliest polarity effect was the observation that the hardening curves obtained in bending did depend on which surfaces were in tension and in compression respectively. This was first related to the velocity of the majority dislocations necessary to account for the imposed curvature of the sample according to Nye's formula [41]. In bending, dislocation loops are thought to be generated first at top and bottom surfaces, where the applied stress is the largest and, depending on the type of bending, either $\alpha$ or $\beta$ dislocations will move towards the centre of the sample. Thus it seems probable that the difference in the flow stress in the two types of bending directly stems from the different mobilities of $\alpha$ and $\beta$ dislocations. Sumino and Shimizu [42, 43] by very careful experiments in InSb proved that this was not the true explanation.

First, they point out that, as deformation proceeds, dislocations should multiply in the bulk [44] and all types of dislocations move simultaneously, which would smear out the initial difference in the flow stress, in clear contradiction with experiments. Second, they pointed out that the rate of increase of the majority or minority dislocations, necessary to bring about the curvature, i.e. $\alpha$ or $\beta$ dislocations, could not result from the motion of $\alpha$ or $\beta$ dislocations themselves but instead by the motion of screws which should be rate controlling in both types of bending. No difference, accordingly, was found in the magnitude of activation parameters characterizing the temperature and strain rate sensitivities of the yield stress. The key was given by the observation that in the so-called $\beta$ bending, dislocations of secondary slip systems were activated. Geometrical considerations showed that the type of bending can be reversed between the primary slip plane and some of the secondary slip planes. Thus, in $\beta$ bending, fast $\alpha$ dislocations of secondary slip systems were activated and acted as forest dislocations for primary dislocations. The difference in the activity of secondary slip systems resulted in a persistent difference in the flow stress even after the lower yield point. Only in the very early stages is the difference in flow stress partly due to the difference of increase of the screw dislocation density, which is closely related to the difference in the mobility and $\alpha$ and $\beta$ dislocations.

The polarity effect was observed in uniaxial compression of nearly dislocation-free InSb crystals by Kesteloot and Di Persio, using a specific surface treatment to promote one type of dislocation [45]. Dislocation multiplication was biased by severe grinding of one free surface. Depending on the polarity of the abraded surface, $\alpha$ or $\beta$ dislocations 
of the primary slip system only can.move towards the interior of the sample. A significant difference in the flow stress was found between the $\alpha$-(soft) case and the $\beta$-(hard) case. Investigation of the dislocation structure by $\mathrm{X}$-ray topography yielded quite the same explanation as Sumino and Shimizu for the case of bending : in the soft case, fast $\alpha$ dislocations created long screw dislocations which are the predominant type (Fig. 9). In the hard case, deformation did not proceed by the motion of $\beta$ dislocations from the abraded surface but by $\alpha$ dislocations of secondary slip systems.

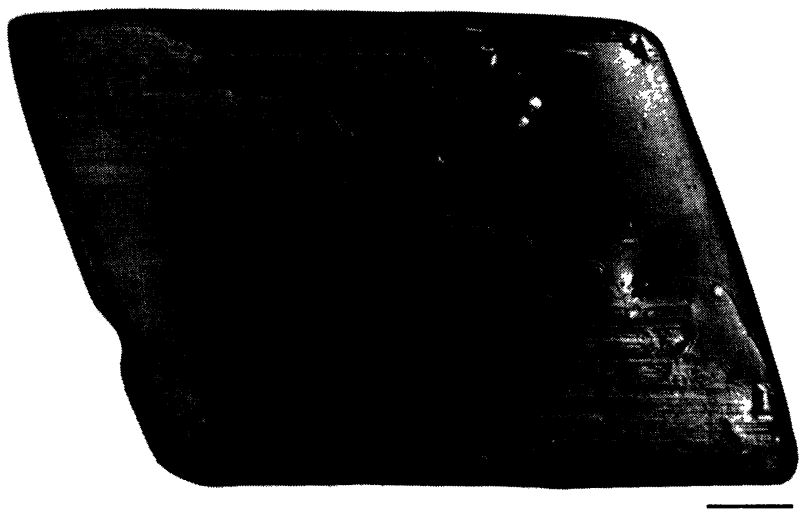

Fig. 9. - Microdeformation of InSb $\left(\dot{\gamma} \sim 1.6 \times 10^{-5} \mathrm{~s}^{-1}\right.$, $\left.T=222^{\circ} \mathrm{C}, \quad \tau \sim 5 \mathrm{MPa}\right)$. Primary dislocations were created at the abraded surface on the left side of the sample and consist mainly of long screw segments developed by the fast motion of $\alpha$ dislocations. X-ray topograph marker, $500 \mu \mathrm{m}$. R. Kesteloot [45].

All these experiments show that the situation is complex and explanations taking only one type of dislocations into account are too simple to describe the mechanical behaviour of III-V compounds. One should use rather the extension of the model of Haasen, given by Steinhardt and Haasen [46], who have considered the contribution of all dislocation types to the strain rate.

Equation (2) is replaced by :

$$
\dot{\gamma}=b\left(\rho_{\mathrm{m}, \alpha} v_{\alpha}+\rho_{\mathrm{m}, \beta} v_{\beta}+\rho_{\mathrm{m}, \mathrm{s}} v_{\mathrm{s}}\right) .
$$

Equation (4) by :

$$
\tau_{\mathrm{eff}}=\tau-A \sqrt{\rho_{\mathrm{m}, \alpha}+\rho_{\mathrm{m}, \beta}+\rho_{\mathrm{m}, \mathrm{s}}} .
$$

As in expanding loops, screw dislocations are supposed to be generated by moving $60^{\circ}$ dislocations and vice versa, so that equation (5) is replaced by the set of equations :

$$
\begin{aligned}
& \frac{\mathrm{d} \rho_{\mathrm{m}, \mathrm{s}}}{\mathrm{d} t}=K_{\alpha} \rho_{\mathrm{m}, \alpha} v_{\alpha} \tau_{\mathrm{eff}}+K_{\beta} \rho_{\mathrm{m}, \beta} v_{\beta} \tau_{\mathrm{eff}} \\
& \frac{\mathrm{d} \rho_{\mathrm{m}, \alpha}}{\mathrm{d} t}=\frac{\mathrm{d} \rho_{\mathrm{m}, \beta}}{\mathrm{d} t}=\frac{1}{2} K_{\mathrm{s}} \rho_{\mathrm{m}, \mathrm{s}} v_{\mathrm{s}} \tau_{\mathrm{eff}} .
\end{aligned}
$$

(This neglects the change in velocity due to the sequence of partials.) Assuming $K_{\alpha}=K_{\beta}$ and neglecting the initial dislocation densities, one finds :

$$
\begin{gathered}
\rho_{\mathrm{m}, \mathrm{s}} \sqrt{K_{\mathrm{s}} v_{\mathrm{s}}}=\rho_{\mathrm{m}, \alpha} \sqrt{2 K_{\alpha}\left(v_{\alpha}+v_{\beta}\right)} \\
\rho_{\mathrm{m}, \alpha}=\rho_{\mathrm{m}, \beta} \\
\dot{\gamma}=\rho_{\mathrm{m}} b q \sqrt{\frac{1}{2}\left(v_{\alpha}+v_{\beta}\right) v_{\mathrm{s}}}
\end{gathered}
$$

where $\rho_{\mathrm{m}}$ is the sum of densities of mobile $\alpha, \beta$ and screw dislocations, and $q$ a dimensionless parameter which is equal to unity if one assumes $K_{\alpha}=K_{\beta}$. Then equation (19) simplifies to

$$
\dot{\gamma}=\rho_{\mathrm{m}} b \sqrt{\frac{1}{2} v_{\alpha} v_{\mathrm{s}}} \text { since } v_{\alpha} \gg v_{\beta} \text {. }
$$

From this analysis the strain rate is independent of the velocity of $\beta$ dislocations, which however contribute to $\rho_{\mathrm{m}}$, and depends on both $v_{\alpha}$ and $v_{\mathrm{s}}$ via a geometric average.

\subsection{DERIVATION OF ACTIVATION PARAMETERS AND} COMPARISON WITH VELOCITY MEASUREMENTS. Similar thermodynamic analysis as reported in a previous section for $\mathrm{Si}$ has been recently performed for several compounds : InSb [47], InP [48] and GaAs $[48,49,50]$. In most cases, $\Delta G$ was determined by the integration of the activation volumes measured at the (lower) yield stress in pre-strained single crystals.

Table I lists the values obtained for $\Delta G . \Delta G_{0}$ is the Gibbs free energy of activation at zero stress which is important for the characterization of elementary mechanisms and can be compared with theoretical

Table I. - Activation enthalpies determined by integrating activation volumes. Except for $\mathrm{Si}$ and InSb, $\Delta G$ is much higher than the activation energy for dislocation velocity, $Q$, at comparable stress (see Tab. III, part I). In S doped InP, $Q \cong 1.6 \mathrm{eV}$ [51].

\begin{tabular}{|l|c|c|c|c|}
\hline Material & $\begin{array}{c}\Delta G_{0} \\
\mathrm{eV}\end{array}$ & $\begin{array}{c}\Delta G(\tau) \\
\mathrm{eV}\end{array}$ & $\begin{array}{c}\tau \\
\mathrm{MPa}\end{array}$ & Réf. \\
$\mathrm{Si}$ & $2.5-2.6$ & 2.20 & 6.7 & \\
$\mathrm{GaAs}$ & 3 & 2.05 & 11 & {$[7]$} \\
& & 2.15 & 20 & {$[49]$} \\
$\mathrm{GaAs}$ & 2.45 & 2 & 30 & \\
GaAs & $2.1-2.25$ & & & {$[50]$} \\
InSb & 1.15 & & & {$[47]$} \\
InP & $2.6-3$ & $\sim 1.65$ & 10 & {$[47]$} \\
InP & $\sim 3.2$ & $\sim 1.5$ & 20 & {$[48]$} \\
(S doped) & & & 10 & \\
\hline
\end{tabular}


calculations for $E_{d k} / 2+W_{\mathrm{m}}$ for example. The direct check of the consistency between activation parameters derived from macroscopic tests and velocity measurements however can be done only in the same stress range. We have also listed $\Delta G(\tau)$ to be compared with the activation energies for dislocation glide at about the same stress (part I, Tab. III).

A clear result is that in contradiction with the fair agreement obtained in $\mathrm{Si}, \Delta G$ values compare rather poorly with $Q$, whatever type of dislocation is considered. $\Delta G$ is higher by as much as a factor of two than $Q$. It is clear that such a large discrepancy cannot be accepted and is well beyond error bars claimed by authors using the two techniques : either the error in one kind of experiment at least is underestimated or the «Gibbs free energy » derived from compression tests is not that characterizing dislocation glide.

Of course the situation in compounds may be complicated by the large difference in mobilities of the different types of dislocations. However the activation energies for $\alpha, \beta$ or screw dislocation velocities are rather similar and whatever the averaging procedure to relate dislocation dynamics to the flow stress, the resultant apparent activation energy should not be higher than the highest $Q_{\alpha}, Q_{\beta}$ or $Q_{\text {s. }}$.

In $\mathrm{Si}$, it is very clear that velocity measurements give a value of $Q$ much more accurate that $\Delta G$ derived from stress relaxation tests. Is it possible that velocity measurements are not as reliable in compounds? It is indeed more difficult to measure the mobilities of slower dislocations of the $\beta$ or screw types and the accessible temperature range is commonly rather narrow. It could be argued also that velocities were measured most often by the double etch technique whilst the recent work of Jacques and George in S doped InP [51] casts a doubt about the identity of near surface and bulk mobilities. At that time, however, this near surface enhancement of dislocation velocity had not been observed in any other III-V and it does not lead to a very different activation energy.

The uncertainty in activation volume measurements has been mentioned before. According to our own experience common errors would lead to excess values, thus to an overestimation of $\Delta G$ (as it is suspected). In some cases (but not all) the pre-strain suppresses the yield peak, making the localization of the yield stress difficult. Of course in case of appreciable hardening a correction should apply to the apparent activation volume [52]. The implicit assumption of a quasi stress independent prefactor can also be questionned. If in addition to the stress dependence of $\Delta G$, the prefactor varies according to a power law as in the general empirical relation:

$$
\dot{\gamma} \sim\left(\tau / \tau_{0}\right)^{n} \exp (-\Delta G(\tau) / k T)
$$

then the apparent. activation volume is :

$$
\frac{n k T}{\tau}+V
$$

with $n \sim 2$ as expected from a classical treatment on the stress dependence of $\rho_{\mathrm{m}}$, the first term can be important at low stress (In GaAs, $2 k T / \tau=10 b^{3}$ at $\tau=30 \mathrm{MPa}, T=420^{\circ} \mathrm{C}$ ). It should therefore be very useful to estimate the mobile dislocation density as in Si.

\subsection{TEM INVESTIGATION OF DISLOCATION CON-} FIGURATIONS. - Available observations of the dislocation content in III-V compounds deformed at the lower yield point are very seldom and purely qualitative. The most typical feature consists of very long screw dislocations, as expected in view of the fast motion of $\alpha$ dislocations. (Only in p-type GaAs and n-type InP, in agreement with velocity data, a more homogeneous distribution is observed between the different dislocation types.) Recently, an in situ observation of a single ended source in the HVEM has been reported by Fnaiech [44]: $\alpha$ dislocations and the pole mechanism is rate controlled by the slowest $\beta$ or screw dislocations ;

It may be noticed that observations so far have been made either at a too high temperature and after unloading so that the dislocations have lost much of their preferred crystallographic orientations or at very low temperature i.e. at very high stresses and then dislocations have changed their dissociation widths and single Shockley partials may be important. It must be recognized that observations of the loaded state in medium conditions are difficult due to dislocation motion in thin foils under the electron beam [50].

\subsection{THE YIELD REGION IN III-V COMPOUNDS AND} BCC METALS. - The predominance of long screw dislocations in TEM micrographs suggests a comparison between III-V compounds and bcc metals at low temperature.

Below $\sim 0.15 T_{\mathrm{m}}$ bcc metals exhibit a preplastic stage (stage 0 ) with a high hardening rate before the «macroscopic» yield stress [53]. At larger strains a unique stage with a very low hardening rate is observed. The macroscopic yield stress strongly decreases with increasing temperature and is very sensitive to the stress orientation and to minute concentrations of impurities. These features are explained by the high friction stress felt by screw dislocations due to the non-planar « dissociation » or spreading of their core. Thus a screw dislocation moves by a double kink mechanism with a much smaller velocity than mixed dislocations. In stage 0 , existing mixed dislocations are progressively exhausted but their motion creates a large density of 
screws whose mobility increases with the applied stress.

In semiconductors the lattice friction has a different origin since it is created by the breaking of covalent bonds and is, consequently, effective for all dislocations types. In III-V compounds, except for some special doping, the fast motion of $60^{\circ} \alpha$ dislocations creates long screws as in the preplastic stage of bcc metals. There are however several important differences. The kink migration energy is believed to be very small in metals, contrarily to covalent crystals. In most experiments the screw dislocation velocity is proportional to its length, $L$ (see part I, Sect. 2) in bcc metals whilst in semiconductors the length independent regime of kink-kink annihilation is established. In bcc metals, and not in semiconductors, a major effect of impurities is to change the dislocation velocity via the determination of $L$.

Another difference lies in the ability of cross-slip, which should be easier in bcc metals due to the nonplanar core structure of screws and which requires a constriction in semiconductors as in fcc metals.

Concerning the shape of the $\tau$ - $\gamma$ curve the difference between parabolic hardening and the yield drop is probably due chiefly to different starting dislocation densities. It could be interesting to study the onset of plastic flow in compounds pre-strained at higher temperatures to see whether bcc and III-V crystals have a really similar behaviour. As a matter of fact the yield drop is totally suppressed in compounds after a $1 \%$ pre-strain that would have left a marked yield drop in silicon. This has been observed recently in GaSb [54] and GaAs [49] for example. This difference between ESC and CSC could be ascribed to the specific conditions of operation of dislocation sources in compounds [50].

\section{The influence of doping on plastic properties at medium temperatures.}

4.1 THE NECESSITY OF NOT TOO HIGH DEFORMATION TEMPERATURES AND THE WAY TO DO IT. The analysis of the effect of electronic doping on plastic properties of SC requires not too high deformation temperature or high strain rate to prevent any diffusion effects which promote precipitation of impurities on dislocations. This is well illustrated through the studies of Siethoff and coworkers. Siethoff [55] studied heavily doped $\mathrm{Si}$ with phosphorus and boron $\left(\mathrm{P}: n=5 \times 10^{19}\right.$ to $1.35 \times 10^{20}$ $\mathrm{cm}^{-3}, \mathrm{~B}: p=4 \times 10^{19}$ to $1.25 \times 10^{20} \mathrm{~cm}^{-3}$ ) in the temperature range $900{ }^{\circ} \mathrm{C}-1100^{\circ} \mathrm{C}$ in compression with strain rates varying between $10^{-2}$ to $10^{-4} \mathrm{~s}^{-1}$. Those high dopant concentrations are necessary to still get an extrinsic character at these temperatures. Two different behaviours were observed following the strain rate range. At higher strain rates
( $\dot{\gamma} \geq 5 \times 10^{-3} \mathrm{~s}^{-1}$ ) the lower yield stress was found to depend on the type of doping. However, if the measured activation energies : $2.3 \mathrm{eV}$ for pure $\mathrm{Si}$, $2.3 \mathrm{eV}$ for $p$-type, $2 \mathrm{eV}$ for $n$-type show the same trend as for dislocation velocity measurements (cf. Sect. 4.4, part I), the order of the yield stresses

$$
\tau_{\ell \mathrm{y}}^{p}>\tau_{\ell \mathrm{y}}^{n}>\tau_{\ell \mathrm{y}}^{i}
$$

is not expected from dislocation velocity measurements. At lower strain rates marked deviations from this behaviour are observed: the lower yield stress becomes independent of strain rate but still depends on temperature and linearly on doping concentration whatever the nature of the dopant :

$$
\tau_{\ell_{\mathrm{y}}}^{\ell_{1}} \alpha C_{0} \exp \frac{U_{\ell_{\mathrm{y}}}^{0}}{k T}
$$

Together with the disappearance of the upper yield point at high dopant concentration, serrations on the deformation curves were interpreted as a PortevinLe Chatelier effect. This was explained on the basis of strain ageing i.e. successive pinning and depinning of dislocations from impurity clouds, the interaction energy between dislocations and solute atoms $U_{l_{y}}^{0}$ being partly electrostatic.

An analogous study by Brion et al. [56] on Ge doped with $\mathrm{Ga}$ and As $\left(p=4 \times 10^{19}\right.$ to $9 \times 10^{19} \mathrm{~cm}^{-3}$ and $n=1.3 \times 10^{19} \mathrm{~cm}^{-3}$ respectively) deformed at temperature between $500{ }^{\circ} \mathrm{C}$ and $900^{\circ} \mathrm{C}$ and strain rates $5 \times 10^{-5} \mathrm{~s}^{-1}<\dot{\gamma}<5 \times 10^{-2} \mathrm{~s}^{-1}$ leads to the same conclusions. However three distinct regions have been differentiated (Fig. 10). A high strain rate region $(c)$ can be related to electronic doping

$$
\tau \S_{\mathrm{y}} \alpha \dot{\gamma}^{1 / m+2} \exp \left(\frac{Q}{2+m} / k T\right)
$$

( $m, Q$ as in the model of Haasen Sect. 2.1)

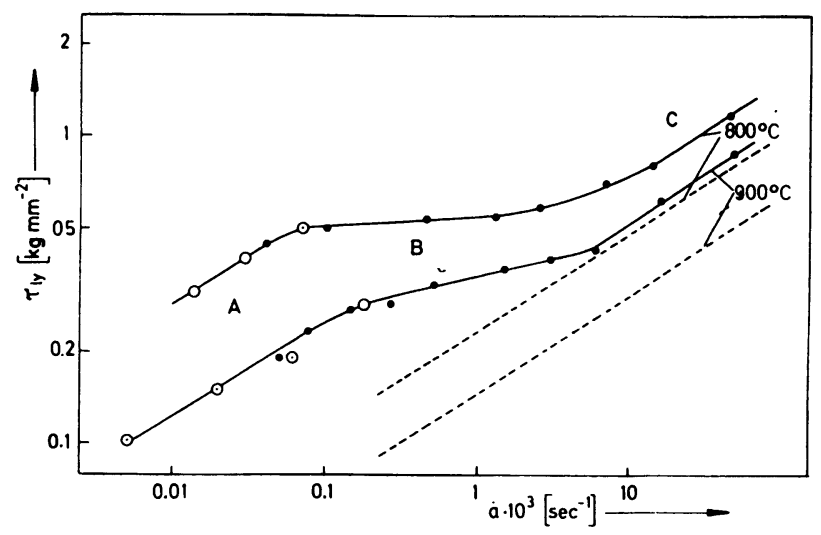

Fig. 10. - Lower yield stress $v s$. strain rate for $\boldsymbol{n}$ doped $\mathrm{Ge}$ (solid lines) and pure Ge (broken lines) (after Brion et al. [56]). 
At medium strain rate the Portevin-Le Chatelier effect is found :

$$
\tau^{B}=c \frac{k T}{b^{3}} \exp \left(\alpha \frac{U_{0}}{k T}\right)
$$

which is the critical stress for unpinning dislocations from their solute atmospheres. At higher $T$ and smaller strain rates the impurity clouds are dragged along in a microcreep process which is controlled by the diffusion of solute atoms, moving along with dislocations :

$$
\tau^{A} \alpha \dot{\gamma}^{1 / 3} c^{1 / 3} \exp \left(\frac{\alpha U_{0}+U_{\mathrm{s}}}{3 k T}\right)
$$

where $U_{0}$ is the binding energy, $\alpha<1, U_{\mathrm{s}}$ the activation energy for solute atom diffusion.

These experiments show that lower temperature studies are better suited for studying the doping effect on plasticity. Furthermore lower dopant concentrations are necessary at lower temperature to get extrinsic samples, which can avoid precipitation effects (impurity cluster formation). Typically, dislocation velocity measurements in $\mathrm{Si}$ have shown that the doping effect is important as soon as temperature is below $600{ }^{\circ} \mathrm{C}$ for donor concentration in the range of $10^{18} \mathrm{~cm}^{-3}$, the effect increasing when temperature decreases. To be able to compare dislocation velocity measurements and plastic deformation in doped $\mathrm{Si}$, it is necessary to get plasticity below $600^{\circ} \mathrm{C}$. As evidenced above, this temperature range can be investigated using standard compression tests after a suitable pre-strain which strongly erases the yield point phenomena. Another possibility - namely, repeated yielding experiments - can be viewed as an extension of the pre-straining technique. In this procedure the sample is heated to the highest temperature, yielded to a few percent of strain and usually unloaded before the temperature is lowered and the specimen yielded again. The cycle is repeated at lower and lower temperatures until the specimen fails. This procedure has been used for metals in which the increment of the effective stress was measured (see [57] for experimental requirements).

It must be stressed that the comparison of the flow stress measured without or with predeformation in the temperature range where this is possible shows significant differences. The yield stresses measured in pre-strained samples depend on the amount of pre-strain and on the temperature difference between pre-deformation and deformation, even when a yield point still subsists. This raises the problem of what is really measured at the lower yield point. Once again, it is sure that $\tau_{\ell y}$ depends on the initial dislocation density, contrarily to the theory of Alexander and Haasen.
'4.2 THE EFFECT OF DOPING AT MEDIUM TEMPERATURES IN ESC. - By using successive yielding experiments Demenet et al. [58] succeeded in deforming $\mathrm{Si}$ down to $380^{\circ} \mathrm{C}$. The influence of doping on mechanical behaviour was studied on $n$-type $\left(6 \times 10^{18} \mathrm{P}\right.$ at.cm $\left.{ }^{-3}\right) p$-type $\left(10^{18} \mathrm{~B}\right.$ at.cm $\left.{ }^{-3}\right)$ and intrinsic $\left(n \cong 10^{14} \mathrm{~cm}^{-3}\right) \mathrm{Si}$ between $380^{\circ} \mathrm{C}$ and $650^{\circ} \mathrm{C}$ at strain rates $\dot{\gamma} \cong 2 \times 10^{-6} \mathrm{~s}^{-1}$ on $\langle 123\rangle$ oriented crystals. The yield stresses were found to be in the sequence

$$
\tau_{\mathrm{i}} \geq \tau_{p}>\tau_{n} \quad \text { (Fig. 11) }
$$

in agreement with dislocation velocity measurements. For the comparison, the formalism of Alexander and Haasen was used, which yields for the ratio between the lower yield stresses of two kinds of samples:

$$
\frac{\tau_{\ell_{y}}^{1}}{\tau_{\ell_{y}}^{2}}=\left(\frac{B_{2}}{B_{1}}\right)^{1 / m+2} \exp \left(\frac{Q_{1}-Q_{2}}{(m+2) k T}\right) .
$$

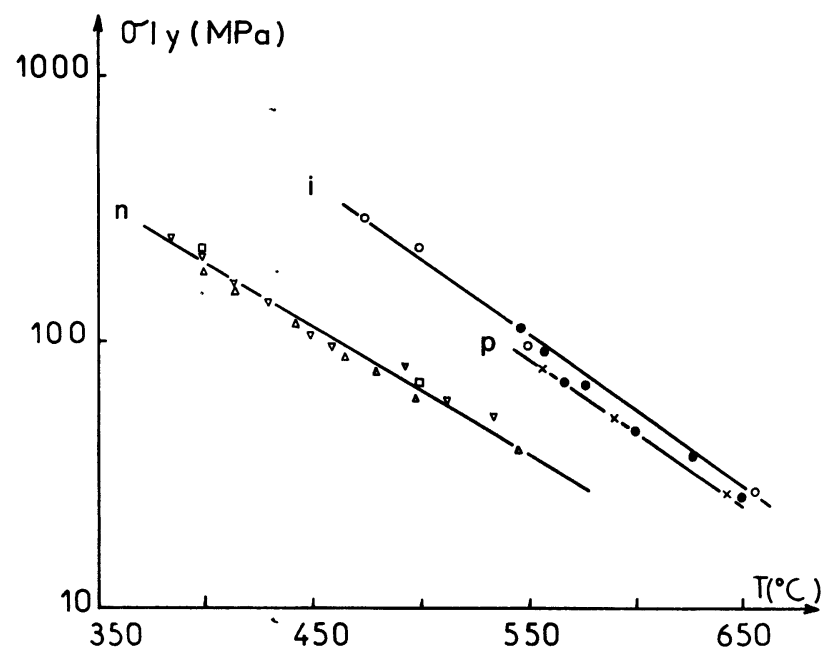

Fig. 11. - Temperature dependence of the engineering flow stress at the lower yield point for intrinsic (i), $n$ and $p$ type silicon (after Demenet et al. [58]).

With the data of velocity measurements $B, Q, m$ (assuming that in the range of interest the stress dependence of $m$ can be neglected), a good fit has been obtained between calculated and experimental ratios for intrinsic and $n$ doping although the order of magnitude of stress were not the same in velocity measurements. Using different strain rates $m$ and $Q$ values were obtained for each doping. If there is a good agreement for $Q / m$ values for the three sets of doping, $m$ and $Q$ values were only in agreement with velocity data for $p$ and $n$-type $\mathrm{Si}$. For intrinsic $\mathrm{Si}, m$ and $Q$ values are very scattered and higher than velocity data. This was explained by the fact that at high doping level the macroscopic deformation is 
more homogeneous. (TEM studies have proved that perfect dislocation velocities had to be considered since dislocations remained narrowly dissociated even at the high stress level reached in these experiments).

4.3 THE EFFECT OF DOPING AT MEDUM TEMPERATURES IN COMPOUNDS. - In compounds, the influence of doping on plasticity in GaAs is rather well documented. In particular, although the interpretation is more difficult than in ESC, due to the existence of several dislocation types ( $\alpha, \beta$, screws) whose velocities are very different, plasticity and dislocation mobility have been studied in the same range of temperature and stress. Sazhin et al. [59] were among the first to show that the upper yield stress was increased by increasing the amount of $n$ carriers, whereas $p$ doping has a minor effect (Fig. 12). The activation energies increased from $p$ type to $n$-type : $1.10 \mathrm{eV}$ to $2.66 \mathrm{eV}$ and some inconsistencies were reported in the stress exponent. Laister and Jenkins [60] report the same tendency but very different activation energies which depend also on heat treatments of samples. Using compression at constant force rate Swaminathan and Copley [61] found :

$$
\tau_{n}>\tau_{\mathrm{i}}>\tau_{p}
$$

between $523 \mathrm{~K}$ and $823 \mathrm{~K}$.

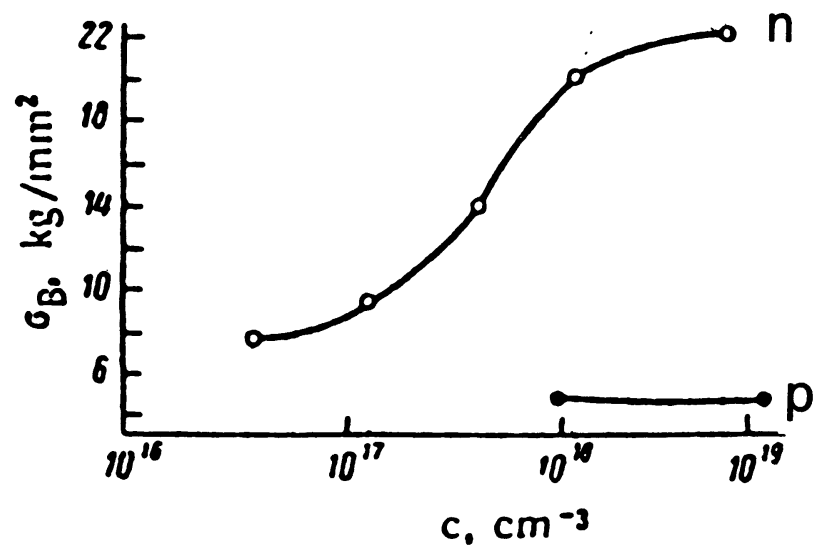

Fig. 12. - Dependence of the upper yield stress of GaAs on the concentration of donor or acceptor impurities $(n)$ : Te doped, (p) Zn doped (after Sazhin et al. [59]).

But the most coherent study was performed by Steinhardt and Haasen [46] who studied both the macroscopic plasticity by compression creep on $\langle 123\rangle$ axis and dislocation velocity by double etching on Te doped $\left(n=2 \times 10^{18} \mathrm{~cm}^{-3}\right), \mathrm{Zn}$ doped $\left(p=3 \times 10^{18} \mathrm{~cm}^{-3}\right)$ and undoped. The maximum strain rate of the $\mathrm{S}$ shaped creep curve was taken as the quantity characterizing the plasticity of the crystals [6]. It was shown that p-type GaAs was softer and $n$-type harder than intrinsic in the range $300{ }^{\circ} \mathrm{C}-650^{\circ} \mathrm{C}$. The change of the maximum creep rate with doping was mainly ascribed to a variation of the activation energy $\left(Q_{p}=1.3 \mathrm{eV}, Q_{\mathrm{i}}=1.5 \mathrm{eV}\right.$, $Q_{n}=2.2 \mathrm{eV}$ ) in agreement with velocity measurements at the same stress $\tau \cong 10 \mathrm{MPa}$. Zn was found to increase the creep rate whereas it decreases the velocity of $\alpha$ dislocations, therefore the maximum creep rate cannot be directly related to the velocity of $\alpha$ dislocations alone, although they are the faster in the three types of crystals. The authors used the extension of Haasen theory given in section 3.3 for $n$-type and intrinsic GaAs and the usual $\dot{\gamma}=$ $\rho b \bar{v}$ in $p$-type material where the three types of dislocations have nearly equal velocities. This model describes very well the creep rate at $400{ }^{\circ} \mathrm{C}$. However no observation of substructures was performed, which would have been very interesting, the model predicting different densities in $n, p$ and intrinsic crystals. In $n$-type and intrinsic GaAs the low mobility of screw dislocations should promote high internal stress and numerous cross-slip events.

Some recent other experiments have been performed on $\operatorname{GaAs}(n, \mathrm{i}, p)$ [50] and $\operatorname{InP}(n, \mathrm{i})$ [48] with the aim of reaching lower temperatures. InP $\left(n=10^{19} \mathrm{~cm}^{-3}(\mathrm{~S})\right.$ and $\left.n=10^{16} \mathrm{~cm}^{-3}\right)$ was studied between $300^{\circ} \mathrm{C}$ and $750{ }^{\circ} \mathrm{C}$ at $\dot{\gamma}=10^{-4} \mathrm{~s}^{-1}$ after pre-strain in the athermal plateau. GaAs $(n=$ $2 \times 10^{18} \mathrm{~cm}^{-3}$ (Se), $n=10^{14} \mathrm{~cm}^{-3}, p=10^{18} \mathrm{~cm}^{-3}$ (Zn)) was studied in the same way between $150^{\circ} \mathrm{C}$ and $550{ }^{\circ} \mathrm{C}$ at $\dot{\gamma}=2 \times 10^{-5} \mathrm{~s}^{-1}$. These two studies show that the strain rate sensitivity in this range of temperature and stress cannot be anymore related to Haasen theory. These experiments have been analysed using the formalism of thermal activation (Sect. 2.2.2) in order to get $\Delta G_{0}$, the Peierls barrier at $0 \mathrm{~K}$. As pointed out in section 3.2 the $\Delta G(\tau)$ values are much higher than the activation energies of dislocation velocities so that the meaning of the extrapolation to $\Delta G_{0}$ is highly questionable. According to the analysis, the Peierls barrier is higher in $n$ type crystals, consistent with the observation that in this temperature range $n$-type $\mathrm{GaAs}$ as well as $n$ type InP are harder than intrinsic crystals. However the effect of doping on the plasticity of $\mathrm{GaAs}$ is not the same in the whole temperature range investigated. TEM revealed a large density of straight screw dislocations which are thought to control plastic deformation.

From these experiments, one could conclude that the macroscopic plasticity can be explained on the average from the extrapolation of dislocation velocities obtained at lower stresses and higher temperatures. The effect of doping on the flow stress (or the creep rate) is consistent with that on dislocation velocities using classical models to relate both quantities. As in intrinsic compounds, further progress in 
detailed understanding should require a much better characterization of dislocation substructures.

\section{Low temperature plastic deformation.}

Two types of experiments allows plastic deformation to be achieved at still lower temperatures than allowed by pre-deformation treatments : microhardness tests and uniaxial compression tests with a confining pressure. These two kinds of experiments are based on the same principle i.e. superimposing on shear stresses a hydrostatic component of the stress tensor to suppress crack nucleation and propagation. The relation between hardness values and yield stresses is possible but not straightforward. In single crystals, dislocations moving away from the indentation site form regular arrays, known as " rosettes ", which can be made visible by suitable etching. Data from rosettes give more direct information about dislocation motion than the hardness value alone. Microhardness tests have some drawbacks : the stress tensor is not accurately known, which raises difficulties to estimate the effective stress applied to a dislocation. The spatial extension of the plastic region is quite small so that at the lower temperatures, dislocations do not move very far from the indentation site and cracks are simultaneously present. To avoid these difficulties twostep experiments are often conducted : the hardness test is followed by annealing at higher temperature at which dislocations first created at the indentation site move out to release internal stresses.

Compression tests superimposing on the uniaxial stress a hydrostatic pressure, usually applied through a solid confining medium, can provide more information. The stress tensor is well defined and the test can be conducted like a standard one, allowing standard activation parameters such as strain rate sensitivity and activation energy to be measured. However additional difficulties can stem from peculiar experimental requirements : sample jacketing by metals or pressure effects.

\subsection{HARDNESS TESTS.}

5.1.1 ESC. - Si has been widely studied using micro-indentation tests below $700^{\circ} \mathrm{C}$. Eremenko and Nikitenko [62] reported the first study of hardness supplemented by a TEM observation of the dislocation substructures. Below $400^{\circ} \mathrm{C}$ no rosette patterns of dislocations characteristic of the high temperature deformation range are observed after etch pitting. A high density of dislocations is found together with cracks in the vicinity of the impression. Above $400{ }^{\circ} \mathrm{C}$ the hardness of $\mathrm{Si}$ falls quite sharply with increasing temperature whereas below $400^{\circ} \mathrm{C}$ the hardness is only slightly temperature dependent. At temperatures higher than the brittle fracture range $\left(T>300^{\circ} \mathrm{C}\right)$ these authors observed disloca- tion half-loops sufficiently removed from the indentation. Prismatic loops with $a / 2\langle 110\rangle$ Burgers vectors are nucleated at the indenter by a punching mechanism and subsequently glide on $\{111\}$ planes. Dislocations show the usual $\langle 110\rangle$ line orientations associated with Peierls mechanism. In this range of temperature, not only perfect dislocations are observed but also stacking faults and twins on the $\{111\}$ and $\{123\}$ planes. These features can be explained by assuming that in the heterogeneous stress field, dislocation splitting occurs at stresses higher than $\gamma / b$ ( $\gamma$, stacking fault energy). In the course of this study a stress assisted phase transformation has been found between $300^{\circ} \mathrm{C}$ and $400{ }^{\circ} \mathrm{C}$. Platelets of hexagonal phase with $c / a=1.63$, $a=3.86 \AA$ have been found to lie parallel to $\{115\}$ planes. This second phase has been recently analysed by HREM [63].

Hill and Rowcliffe [64] reported a similar study : samples were indented at room temperature and then thinned and annealed in the electron microscope, in some cases after an annealing before thinning. The first effect of annealing, i.e. dislocations moving out of the indentation site, was observed after $1 / 2$ hour at $450{ }^{\circ} \mathrm{C}$. After indentation at' room temperature dislocation substructures consisted of $30^{\circ}$ dislocations parallel to $\langle 121\rangle$. After annealing at $600{ }^{\circ} \mathrm{C}$ long screw segments were found left behind by « edge » fronts moving rapidly. These observations suggest a lower mobility of screw dislocations. Such observations might have not be free of projection effects : the apparent $30^{\circ}$ segments could have been $60^{\circ}$ dislocations lying in the cross slip plane. This is not in contradiction with the fact that screw segments have a lower mobility.

Indentation hardness was also used to study the effect of electronic doping on the macroscopic plasticity. In a study on $\mathrm{Si}$, Roberts et al. [65] reported that at $400^{\circ} \mathrm{C}$ the hardness was independent on doping. However after annealing the samples at the test temperature, rosettes were obtained after etching the sample and their sizes were found to vary consistently with the results of dislocation velocity experiments. Rosettes were larger in heavily doped $\mathrm{Si}$ than in intrinsic and, for the same doping level, rosettes were larger in $n$-type than in $p$-type $\mathrm{Si}$. These data were analysed by modelling the rosettes as arrays of parallel edge dislocations subjected to a stress from the indentation centre plus their mutual interaction stress. It was assumed that in the final state of the rosette, the sum of these stresses on each dislocation was equal to a critical frictional stress for dislocation motion. This analysis gave critical stresses ranging from $100 \mathrm{MPa}$ for intrinsic Si to $70 \mathrm{MPa}$ for heavily doped $\left(2 \times 10^{18} \mathrm{~cm}^{-3}\right) n$-type, to be compared to yield stresses obtained in compression tests under confining pressure reported below.

The same kind of work was performed in the 
temperature range $20^{\circ} \mathrm{C}-500{ }^{\circ} \mathrm{C}$ on the (001) surface of $\mathrm{Ge}$ with different dopings, intrinsic, heavily $p$ and $n$-doped [66]. From $300{ }^{\circ} \mathrm{C}$ to $500{ }^{\circ} \mathrm{C}$, microhardness varies with doping : heavily doped $p$ and $n$-type specimens are respectively harder and softer than intrinsic ones. The biggest variation with doping is at $400^{\circ} \mathrm{C}$ : above and below this temperature, data from the different dopings converge. Contradictorily, the dislocation rosette size depends strongly on doping : rosettes in $p$ and $n$-type Ge are respectively smaller and larger than in intrinsic Ge and the data for the three dopings converge at $500{ }^{\circ} \mathrm{C}$. The modelling and analysis of rosette data do not allow the derivation of a minimum stress for dislocation motion. The authors attribute the failure of the model to the relaxation of indentation stress by the motion of dislocations in rosette arms : this model of the indentation stress field assumes that only elastic deformation takes place outside the region immediately under the indenter. In $\mathrm{Si}$, the relaxation is less important and all dislocations lie within the region where the indentation stress is large compared to dislocation interaction stresses. From the study on $\mathrm{Ge}$, only the dislocation interaction stresses were calculated from the dislocation density at the end of rosette arms, which varies with doping and temperature. The derived values ranging from 6 to $30 \mathrm{MPa}$ have not the right order of magnitude to be compared to the critical resolved shear stresses derived from other macroscopic tests. In those samples,
TEM shows extended stacking faults with individual partial dislocations. The fracture behaviour was also found to depend on doping. The brittle-to-ductile transition temperature is higher for $p$-type, lower for $n$-type. Rosette sizes, dislocation densities and fracture behaviour are consistent with the known variation of dislocation velocity with doping in $\mathrm{Ge}$.

Microhardness tests were also used to generate dislocations at room temperature on a particular geometry of sample subsequently deformed by fourpoint bending at higher temperatures. Twinning was found to be one of the deformation modes of $\mathrm{Si}$ single crystals deformed below $600^{\circ} \mathrm{C}$, in the high stress region of the sample when the uniaxial stress was applied to the specimen along $\langle 100\rangle$ in compression or $\langle 110\rangle$ in tension $[67,68]$. These results are in good agreement with observations in fcc alloys and with the analysis of twin nucleation and growth as a function of the tensile or compressive axis orientation [69]. However the part of the analysis which relies upon the dissociation of Lomer-Cottrell junctions can be questioned since this type of dislocation seems to be undissociated in $\mathrm{Si}$ [70].

5.1.2 CSC. - Observations of rosettes in CSC are of particular interest since following the geometry of the sample (surface orientation, polarity of $\{111\}$ surfaces), dislocations in different areas of the rosettes have different characters, $\alpha$ or $\beta$. For a (100) surface indented with a Vickers indenter

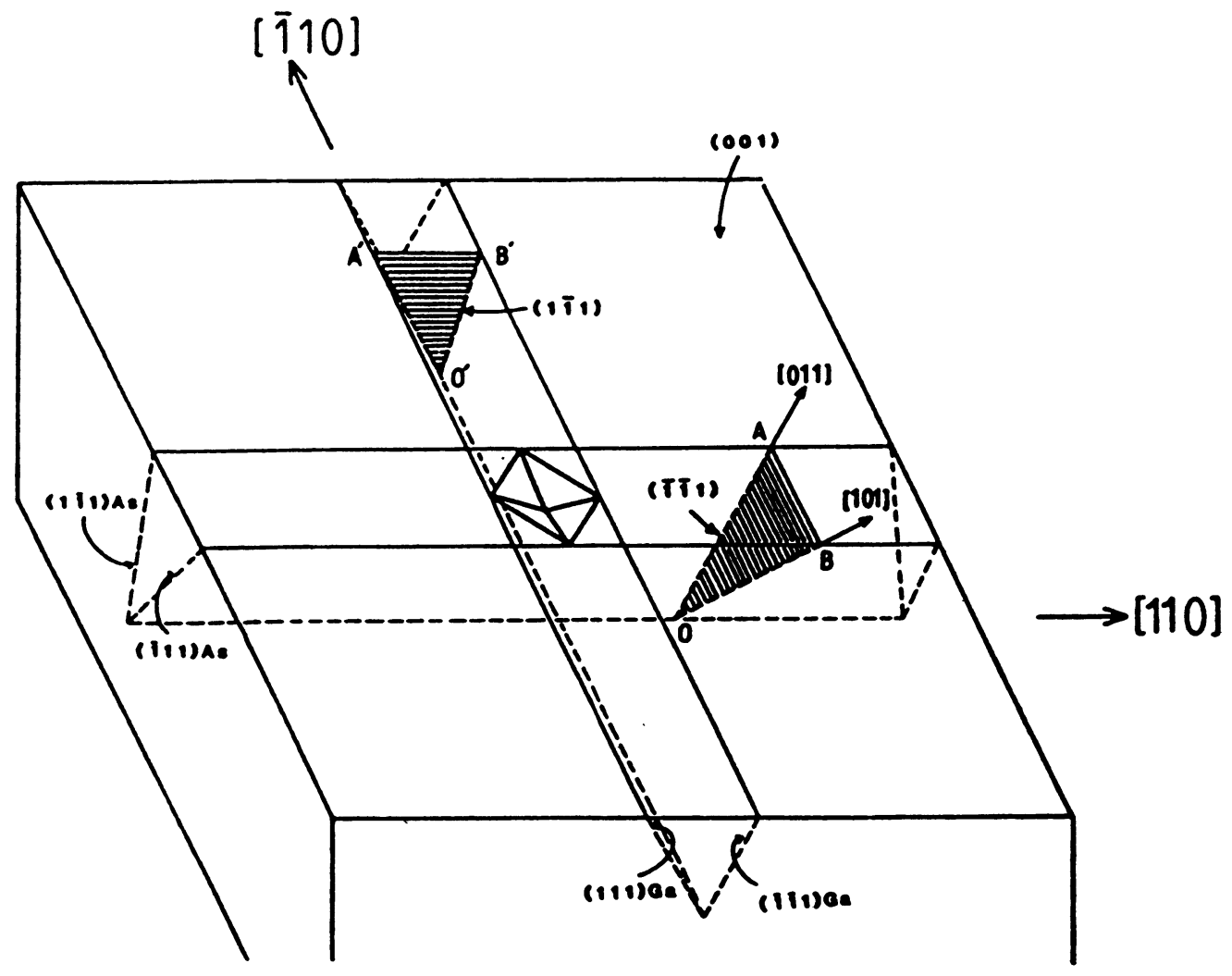

Fig. 13. - Rosette geometry on a (001) surface (after Warren et al. [71]). 
oriented with its diagonal along the two $\langle 011\rangle$ directions, four glide systems are found to operate after prismatic loop generation (Fig. 13). Intersections of these glide systems with the surface along [011] and [011] correspond to the glide of $\alpha$ and $\beta$ dislocations respectively. An asymmetry in the rosette pattern of GaAs [71] or InP [72] between these two directions has been ascribed to the different mobilities of $\alpha$ and $\beta$ dislocations. Using the same geometry Höche and Schreiber reported also this asymmetry which was analysed by TEM [73]. The longer rosette arm was found to be built with partial dislocations bounding extended stacking faults whereas the other one is built with perfect screw dipoles. These authors made no reference to $\alpha$ or $\beta$ dislocation mobilities and explained the different dislocation structures by a difference in stacking fault energies between the different glide planes. It can be suggested that this reflects a larger difference in leading and trailing $\alpha$ partial dislocation mobilities. This observation prevents any simple and quantitative explanation of the $\alpha, \beta$ arm asymmetry.

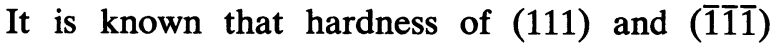
surfaces is generally different. This can be added to the polarity effects mentioned in section 3.1. An extensive study of this problem was conducted by Hirsch et al. [74] who determined the geometry of the plastic zone by observations of slip line patterns and dislocation etch pit patterns at different depths from the indentation surface. Two types of work hardening can be obtained depending on the geometry of slip planes related to a tetrahedron built with $\{111\}$ glide planes. Two types of (111) slip can be defined : one leading to a high work hardening rate by the formation of Lomer-Cottrell locks, the other one leading to a low hardening rate because no such locks are formed. On the assumption that hardness depends on dislocation velocities having the same relative values as those measured at lower stress, the polarity hardness of $\{111\}$ faces of GaAs is explained by the fact that the types of dislocations leading to a low work hardening rate are different at the two opposed surfaces. For n-type GaAs and from the As surface fast As (g), i.e. $\alpha$, dislocations are generated and move on the slip planes giving rise to the lower hardening rate : they penetrate far in the material and lead to a relatively low back stress at a given strain. From the Ga surface the same slip is due to $\mathrm{Ga}(\mathrm{g})$, i.e. $\beta$, dislocations whose penetration in the crystal is smaller, leading to a higher back stress for the same strain. Thus the As surface is softer than the $\mathrm{Ga}$ surface. The same analysis explains why for $p$-type GaAs, the As surface is harder than the Ga surface. This theory gives a good qualitative agreement with experiments but a quantitative relationship between hardness or rosette size and dislocation velocity is complex to derive. It involves the stress dependence of velocities, strain compatibility constraints and work hardening. Furthermore the order of magnitude of the stress reached in microhardness experiments is a hundred times larger than those at which velocity measurements were performed.

At temperatures higher than $200{ }^{\circ} \mathrm{C}$ the average hardness of As and Ga surfaces in p-type GaAs is less than in $n$-type. This can be explained by the fact that the velocities of the various dislocation types in $p$-type GaAs are larger than or equal to those in $n$ type GaAs. However the effect of doping on hardness below this temperature has been found not to be significant, in contradiction with what is expected for the influence of doping on dislocation velocities.

\subsubsection{General comments on hardness tests. - Hard-} ness tests are easy to handle, require small samples and unsophisticated experiments. However from the above review it is clear that quantitative relationships between physical quantities are difficult to derive from such tests. Hardness measurements and rosette extension do not give the same results about the effect of doping, so one must be careful about hardness data obtained at low temperatures [75-77], particularly about the level off of hardness at these low temperatures. Critical stresses for dislocation motion, that can be derived by modelling the stress field around the indentation and rosette data, seem to be relevant only in particular cases.

5.2 DEFORMATION WITH A CONFINING PRESSURE. - Studies have been conducted using this technique on $\mathrm{Si}$ and GaAs only.

\subsubsection{Plastic deformation of $\mathrm{Si}$ under confining} pressure. - Si was investigated at temperatures between $275^{\circ} \mathrm{C}$ and $500{ }^{\circ} \mathrm{C}$ with a confining pressure ranging from $100 \mathrm{MPa}$ to $1500 \mathrm{MPa}$ [78-80]. FZ Si ( $n=10^{13} \mathrm{~cm}^{-3}, n=10^{19} \mathrm{~cm}^{-3}(\mathrm{P})$ ) was deformed along $\langle 123\rangle,\langle 100\rangle$ or $\langle 110\rangle$ at two different strain rates $\dot{\varepsilon}=2 \times 10^{-6} \mathrm{~s}^{-1}$ and $\dot{\varepsilon}=2 \times 10^{-5} \mathrm{~s}^{-1}$. The samples were pre-strained at $400-450{ }^{\circ} \mathrm{C}$ in order to minimize their yield behaviour. Indeed without predeformation samples undergo stresses larger than fracture stress along the transient yielding regime, even using a high hydrostatic pressure (1 $500 \mathrm{MPa})$ as soon as $T$ is lower than $350^{\circ} \mathrm{C}$. For each strain rate the engineering strains at the lower yield point are nearly orientation independent (Fig. 14a). When trying to derive the yield stress resolved on the more stressed glide system, the best fit is obtained when the Schmid factors on the more stressed partials are considered rather than those acting on the perfect parent dislocations. This suggests that the operating slip systems might be $a / 6\langle 112\rangle\{111\}$ rather than $a / 2\langle 110\rangle\{111\}$. This seems to be consistent with the fact that the resolved shear stresses applied to samples during the compression were larger than $\tau_{c}=\gamma / b$, necessary to overcome the string action of 


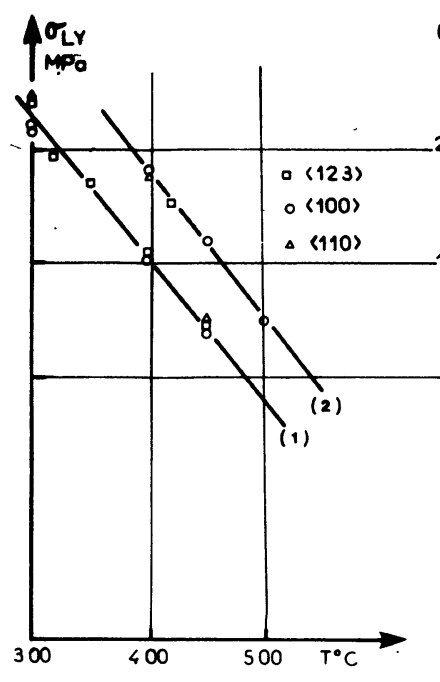

a)

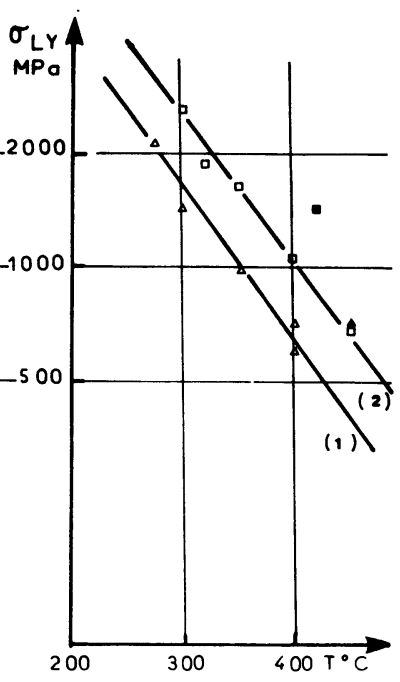

b)
Fig. 14a. - Lower yield stress $\sigma$ vs. $T$ for intrinsic $\mathrm{Si}$ depending on the orientation axis : (1) : $\dot{\varepsilon}=2 \times 10^{-6} \mathrm{~s}^{-1}$; (2) : $\dot{\varepsilon}=2 \times 10^{-5} \mathrm{~s}^{-1}$. Confining pressure $1.3 \mathrm{GPa}$ (after Rabier et al. [80]).

Fig. 14b. - Lower yield stress $\sigma$ vs. $T$ for extrinsic and intrinsic $\mathrm{Si}$, [123] orientation $\dot{\varepsilon}=2 \times 10^{-6} \mathrm{~s}^{-1}$ : (1) : extrinsic $n=10^{19} \mathrm{~cm}^{-3} ;(2)$ : intrinsic $n=10^{13} \mathrm{~cm}^{-3}$. Confining pressure 1.3 GPa (after Rabier et al. [80]).

the stacking fault on partials. However recent TEM observations [79] or [81] show that the dislocation substructures are different at the lower yield point depending on the compression axis (see below).

The effect of doping on mechanical behaviour investigated in the $\langle 123\rangle$ orientation has been found to be important (Fig. 14b). n-type samples were softer than intrinsic ones in agreement with dislocation velocities measured at lower stresses [81]. However the ratio between lower yield stresses of the two types of crystals is surprinsingly constant in the whole temperature range. The homologous temperature (giving the same $\tau_{\ell_{y}}$ ) for doped crystals is $50{ }^{\circ} \mathrm{C}$ lower than for intrinsic $\mathrm{Si}$ and yields the same shift in the brittle-to-ductile transition. Analysis of activation parameters gives a sensitivity of the lower yield stress to the strain rate which is not very different from that deduced at medium temperature i.e. $n=4$. Using this value for $m+2$ in the model of Haasen (Eq. (7) $\S 2.2$ ) gives $Q=1.6 \mathrm{eV}$. This value compares fairly well with that derived from velocity measurements done at low temperatures $\left(325^{\circ} \mathrm{C}-420^{\circ} \mathrm{C}\right)$ at $\tau=300 \mathrm{MPa}$ in intrinsic $\mathrm{Si}$ ( $m=2, Q=1.86 \mathrm{eV}$ ) [82].

At the microscopic scale, the deformation is characterized by slip on the usual (111) glide planes. A TEM investigation of samples deformed along $\langle 123\rangle$ can be summarized as follows [80, 83]. At small strains, deformation is very heterogeneous being localized inside slip bands containing a very high density of perfect dislocations. Several less typical features have been also observed: sparse dislocation bands belonging to a secondary system are detected. In areas where the edge of the dislocation bands intersects the foil surface some quantitative information can be derived on the fine structure of these bands where the dislocations are lower in density. Dislocations have generally the $a / 2$ [011] Burgers vector in the (111) slip plane and exhibit segmented shapes along $\langle 011\rangle$ directions. However very long straight screw dislocations are also seen. Cross slip has been postulated, although the cross-slip plane experiences no shear stress. As a matter of fact, dislocations were observed with an apparent $30^{\circ}$ character but which were in fact $60^{\circ}$ dislocations lying in the cross-slip plane, observed in projection on the primary slip plane. In these areas dislocation splitting leads to quite scattered dissociation widths. Anomalously large dissociation widths, localized at dislocation bends and called « noses » by Wessel and Alexander [84] have been observed. Surprisingly, although large stresses were reached, even for large strains, perfect dislocations remain the major defects, micro-twinning and extended stacking faults appearing as secondary events. This is not the case for the substructure observed in samples deformed along [100] [81] where extended stacking faults and twins are observed at the lower yield point. This could be related to the requirement of junctions formation for twin nucleation [65].

\subsubsection{Plastic deformation of GaAs under confining} pressure. - GaAs was studied between room temperature and $350{ }^{\circ} \mathrm{C}$ at confining pressure of $700 \mathrm{MPa}$ $[85,86]$. Three types of samples were used : intrinsic $n=7 \times 10^{13} \mathrm{~cm}^{-3} ; n=2 \times 10^{19} \mathrm{~cm}^{-3}$ (Se); $p=$ $10^{19} \mathrm{~cm}^{-3}(\mathrm{Zn})$. They were deformed along $\langle 123\rangle$ at strain rate $\dot{\gamma}=2 \times 10^{-5} \mathrm{~s}^{-1}$. Samples were not predeformed since no yield drop has been seen in these experiments. At room temperature the samples exhibit different mechanical behaviours from those reported above at medium temperatures (Sect. 4.3). $n$-type crystals were softer than intrinsic or $p$-type crystals $\left(\tau_{y_{n}}<\tau_{y_{i}}<\tau_{y_{p}}\right)$ in contradiction with velocity measurements at higher temperatures and lower stresses. However, preliminary experiments at $350{ }^{\circ} \mathrm{C}$ show that $\tau_{y_{n}}>\tau_{y_{i}}$ [86]. The strain rate sensitivity gives high $n$ values (ranging from 10 to 50 ) which means that the deformation at room temperature is nearly independent of strain rate. It is clear that extrapolation of dislocation velocity through the Alexander and Haasen formalism $(m \cong 1, n \cong 3)$ cannot be used.

Surface analysis has shown that slip occurs on the usual $\{111\}$ planes, whereas cross-slip is observed at room temperature. At the TEM scale, dislocations 
consist mainly of perfect screw dislocation dipoles left behind $\alpha$ (or $\beta$ ?) dislocations [85, 87]. Although the stress reached in these experiments is higher than the critical stress for the separation of partials, deformation at the yield stress proceeds by perfect dislocations. Large dislocation splitting can only be observed in arrays where the dislocation density is low in both the primary and cross-slip planes in which dislocations escape from primary slip bands. Dissociation widhts cover a very wide range and noses are evidenced. Twinning is observed at large strains [88]. In intrinsic samples, $\alpha$ and $\beta$ dislocations exist with the same density [86].

\subsubsection{Comments on test under confining pressure. -} Plastic deformation tests under confining pressure seem to be very interesting since all the measurements conducted at intermediate temperatures can be made at stresses and temperatures where it is usually impossible to prevent immediate brittle failure. However it is quite difficult to measure stress variations of small amplitude in such experiments due to experimental constraints, mainly unavoidable frictions. This prevents usually comparison between tests made at the same temperature with or without confining pressure. Recent achievements [89] enable these measurements to be performed.

Several effects, absent in standard deformation tests, can exist with a confining pressure : pressure as well as metal jacketing the sample can affect the charge state of the surfaces. (For other possible pressure effects see [90]).

5.3 CONCLUDING REMARKS ON LOW TEMPERATURE DEFORMATION. - In this domain, a comparison between macroscopic experiments and dislocation velocity measurements is difficult to do since, except in $\mathrm{Si}$, the latter have been performed at stresses lower by more than one order of magnitude. At high stresses required for low temperature plasticity, activation energies for dislocation motion are likely to be reduced and the relative velocities of different dislocations may be different.

Furthermore the dislocation density in the plastic zone beneath the indenter is very large, as in slip bands of samples deformed under hydrostatic pressure, particularly at the lowest temperatures investigated. This local high density of deep levels associated with dislocations can lead to severe band bendings and a shift of the relative positions of the Fermi level and the deep levels controlling the dislocation velocity can occur. The high hydrostatic stresses under the indenter or in confined samples can also lead to shift of energy levels [91].

Another problem arises from the high dislocation density : the electronic properties of a sample vary with dislocation densities. $n$-type $\mathrm{Si}\left(10^{13} \mathrm{~cm}^{-3}\right)$ transforms to $p$-type at $700^{\circ} \mathrm{C}$ and $\varepsilon=0.035[92$,
93]. This has been observed also for samples more heavily doped (up to $n=10^{19} \mathrm{~cm}^{-3}$ ) deformed below $450{ }^{\circ} \mathrm{C}$ under confining pressure [94]. One can raise the question of what is the carrier concentration actually seen by a dislocation in crystals compensated by dislocations themselves?

Concerning dislocation substructures obtained after low temperature deformation, slow screw dislocations can be noticed in $\mathrm{GaAs}$, whereas in $\mathrm{Si}$, as the temperature of the deformation decreases the density of straight screw dislocation increases. One can wonder if screw dislocations in CSC and Si have not a similar behaviour provided the deformation temperatures is low enough.

\section{The effect of neutral impurities on mechanical properties.}

6.1 OXYGEN IN SILICON. - The influence of oxygen on the mechanical behaviour of silicon was studied in great detail by Sumino and his group [95, 96]. Using FZ and CZ Si grown with various concentrations of dissolved oxygen atoms, they succeeded in preparing samples with different initial dislocation densities, ranging from zero to $10^{6} \mathrm{~cm} . \mathrm{cm}^{-3}$, by prestraining at $900^{\circ} \mathrm{C}, \dot{\gamma} \sim 10^{-4} \mathrm{~s}^{-1}$ followed by a homogenization treatment $\left(2 \mathrm{~h}\right.$ at $1300^{\circ} \mathrm{C}$ followed by rapid cooling).

At moderate temperature $\left(T \geqslant 900{ }^{\circ} \mathrm{C}\right)$ the results can be summarized as follows (Fig. 15).

In dislocation-free crystals, with chemically polished surfaces, oxygen has little effect on the stress-strain curve. All crystals exhibit a high $\tau_{\mathrm{uy}}$ and a pronounced yield drop. In dislocated crystals - and also in dislocation free samples with mechanically abraded surfaces - oxygen concentrations higher than $\sim 10^{16}$ at. $\mathrm{cm}^{-3}$ have a large effect. The upper yield stress and the stress drop increase with the oxygen content and the stressstrain curve of pre-strained samples of oxygen containing $\mathrm{Si}$ is very close to that of dislocation-free $\mathrm{Si}$. As the oxygen concentration decreases, the expected effect of pre-straining i.e. lower $\tau_{\text {uy }}$ and reduced yield drops, progressively shows up again.

This strengthening is fully consistent with the observation reported above (Sect. 5.5, part I), i.e. oxygen does not change the dislocation mobility but can firmly lock dislocations when at rest or slowly moving by developping Cottrell atmospheres around them : because of this locking, surface damage or initially present dislocations cannot act as efficient sources, or more precisely only a small fraction of them is still able to do so.

Sumino could estimate the locking efficiency as a function of the amount of oxygen segregated per unit length of dislocation core. There is evidence that the locking is more efficient for higher initial concentrations which seems to point to clusters of 


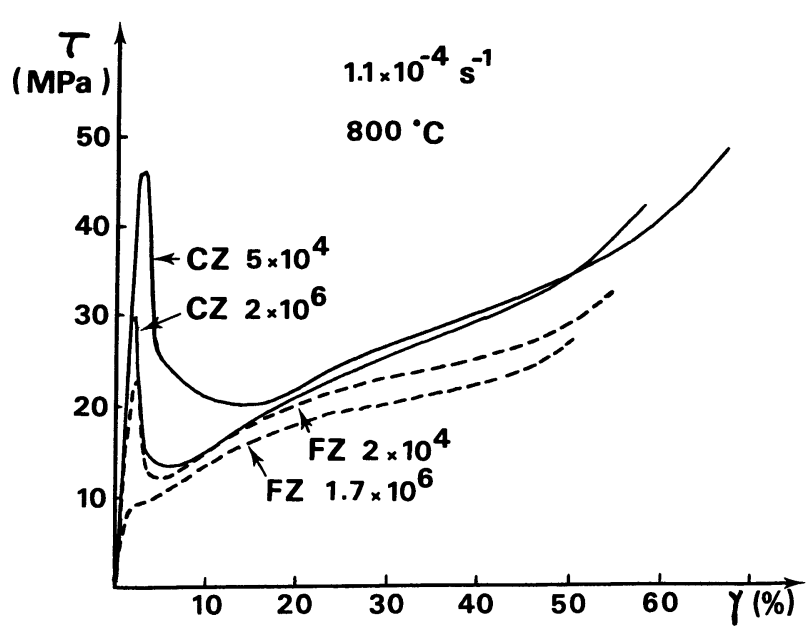

a)

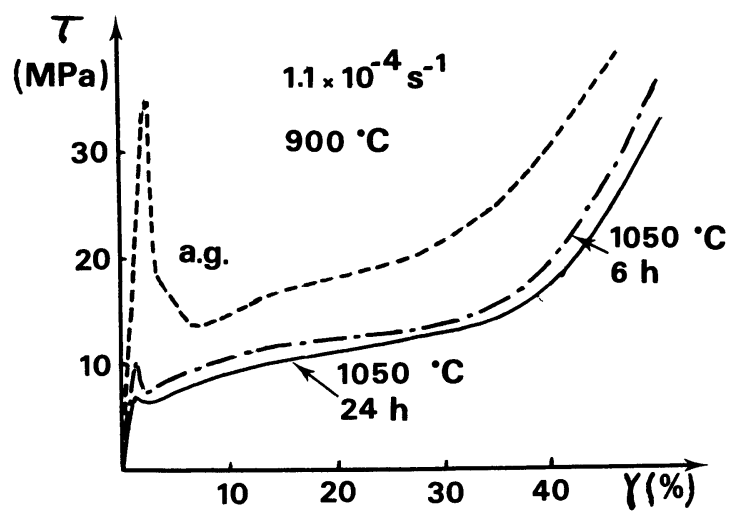

b)

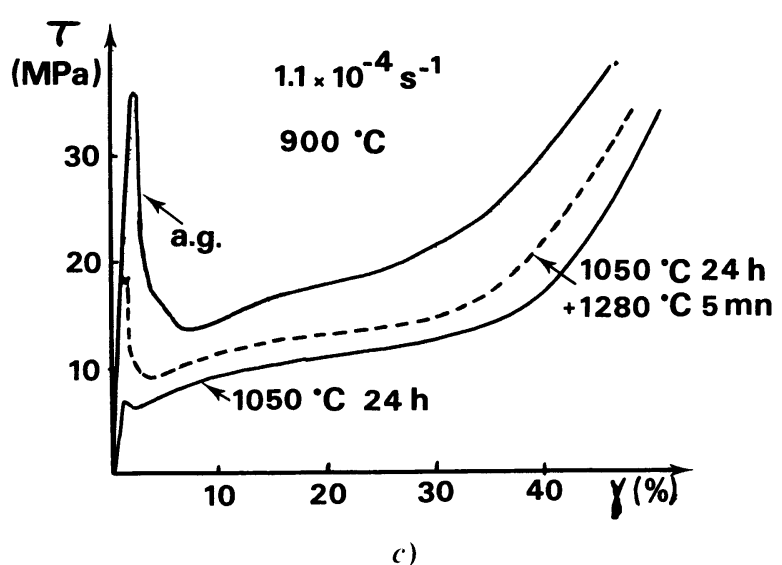

Fig. 15. - The effect of Oxygen on resolved shear-stress $(\tau)$, shear strain $(\gamma)$, curves of silicon, after [94, 95]: a) Comparison between $\tau, \gamma$ curves of FZ silicon and CZ silicon $\left([0] \sim 10^{18}\right.$ at. $\left.\mathrm{cm}^{-3}\right)$. Numerals attached to the curves are the initial dislocation densities. Initial dislocations are much less efficient sources of mobile dislocations in Oxygen containing Si. b) Softening of $\mathrm{CZ}$ silicon at $900^{\circ} \mathrm{C}$ by annealing at $1050^{\circ} \mathrm{C}$, which induces oxygen precipitation (a.g., as grown). c) Partial recovery of $\mathrm{CZ}$ silicon, previously softened by annealing at $1050^{\circ} \mathrm{C}$, after redissolution of oxygen precipitates at $1280^{\circ} \mathrm{C}$ (a.g., as grown). oxygen atoms as the most efficient hardening entities.

On the other hand when supersaturated oxygen is allowed to precipitate due to annealing at $1050{ }^{\circ} \mathrm{C}$ the observed effect is opposite : silicon is softened.

This has been investigated on dislocation-free crystals as a function of the concentration of oxygen. For a given annealing the amount of softening increases with the oxygen content. The softening is closely related to the increase in the density of precipitates and to the decrease in the concentration of interstitially dissolved oxygen. According to Yonenaga and Sumino, precipitates of $\mathrm{SiO}_{2}$ particles are not likely to act as dislocation sources themselves but rather the prismatic dislocation loops that have been punched out from precipitates during annealing at $1050^{\circ} \mathrm{C}$. (Punching of dislocation loops by $\mathrm{SiO}_{2}$ precipitates was first observed by Patel [97].) Of course the efficiency of punched out loops as sources during the deformation at $\sim 900^{\circ} \mathrm{C}$ can be severely decreased if a sufficient fraction of oxygen atoms is still dissolved after the $1050{ }^{\circ} \mathrm{C}$ annealing. The precipitation softening is very small in crystals with low oxygen concentrations.

Sumino et al. have also shown that nitrogen-doped silicon has a much higher yield strength than FZ Si when crystals contain a sufficiently high starting dislocation density [98].

6.2 INDIUM IN GaAs. - In comparison, the study of the influence of isovalent impurity addition on the mechanical properties of III-V compounds is still in its beginning. Very recently two sets of results were given about the effect of In addition on GaAs plastic behaviour. Djemel and Castaing [99] have studied the stress-strain curve at relatively high temperature $\left(600^{\circ} \mathrm{C}<T<800^{\circ} \mathrm{C}\right.$ ) using liquid $\mathrm{B}_{2} \mathrm{O}_{3}$ - also used in the conventional LEC growth technique - to prevent As evaporation. In compression along $\langle 100\rangle-$ i.e. in a multiple slip configuration - they found that, at $\sim 600{ }^{\circ} \mathrm{C}$, when the comparison is possible, $\mathrm{B}_{2} \mathrm{O}_{3}$ drastically softens pure $\mathrm{GaAs}$ compared to the result of a deformation in $\mathrm{Ar}$ atmosphere, while In addition $\left(\sim 5 \times 10^{19}\right.$ at.cm $\left.{ }^{-3}\right)$ makes $\mathrm{GaAs}$ insensitive to the environment. In $\mathrm{B}_{2} \mathrm{O}_{3}$, the flow stress is higher in In alloyed GaAs by a factor of about 3 . With a rather similar experimental procedure Tabache, Bourret and Elliot [100] were able to deform pure and In alloyed $\left(3 \times 10^{19} \mathrm{at}^{\mathrm{cm}} \mathrm{cm}^{-3}\right)$ GaAs up to $1100^{\circ} \mathrm{C}$, in compression along $\langle 123\rangle$ (single slip geometry). They reported a very weak influence of In addition on activation parameters, with a flow stress higher by a factor of two close to the melting point and not significantly changed below $\sim 600^{\circ} \mathrm{C}$. They claimed $\mathrm{B}_{2} \mathrm{O}_{3}$ to have no effect on the flow stress, in clear contradiction to Djemel and Castaing. In view of the differences of In concentrations, initial dislocation density, slip 
geometry, strain rate, all parameters which could be important when compared to the case of oxygen in $\mathrm{Si}$, it is not really surprising that these first two works do not yield coinciding conclusions.

\section{Summary and conclusions.}

Centred on the relationship between dislocation mobility and macroscopic mechanical behaviour, the second part of this review mainly dealt with the yield region of the stress-strain curve and not with later stages appearing at large strains. Main results and comments could be stated as follows.

i) Stress-strain curves of semiconducting materials closely resemble those of fcc metals except for the large initial yield peak associated with the usually very low starting dislocation density and for the marked temperature dependence of yield stresses in a very wide temperature range due to the very large lattice friction caused by the covalent type of bonding.

ii) In this « low » temperature range $\left(T<0.8 T_{\mathrm{m}}\right)$ the relation between the yield stress and the velocity of dislocations is certain but not easy to rationalize. In usual conditions, with non - or very slightly pre-strained samples, dislocations multiply in avalanche at the onset of plastic flow and among available models the best is that of Alexander and Haasen [6], which properly accounts for that multiplication. This model gives a satisfactory description of the yield point in $\mathrm{Si}, \mathrm{Ge}$ and III-V compounds, in doped as well as undoped materials, with a fair agreement between the temperature and strain-rate dependences of yield stresses and the temperature and stress dependences of dislocation velocities. This agreement however relies on extrapolations of available data on dislocation mobilities.

The model of Alexander and Haasen could perhaps be improved by more sophisticated expressions for the multiplication law of dislocations and the effective stress but a major improvement would be to take into account the inhomogeneous nature of the strain and dislocation structure during the yield drop. A very promising approach is the use of bifurcation theory - successfully applied to other non-linear situations in plasticity [101] - . It seems that mathematical difficulties still remain in the application to the yield drop.

iii) The model of Haasen determines microscopic quantities like the mobile dislocation density and the fraction of the applied stress which is effective at the lower yield point. Recently direct measurements of these quantities have been derived from TEM observations in deformed silicon. They were possible however only in a temperature range where the dislocations retain crystallographic $\langle 110\rangle$ orientations, which can be reached at low strain rates after a suitable pre-strain has created a large starting dislocation density. The pre-strain treatment erases the yield peak and it is possible that the model of Alexander and Haasen is not adapted to such situations. It is possible also that dislocation multiplication at low temperature is made more difficult by the absence of cross-slip in ESC. Whatever the cause, results do not agree with the predictions : it is found that nearly the totality of the applied stress is effective at the lower yield point - and not $1 / 3$ and the imposed strain rate is attained by a correspondingly lower dislocation density than the theoretical value.

iv) The model of Alexander and Haasen makes use for the dislocation velocity of a phenomenological law inspired by creep laws where the stress dependence is expressed by a power law with an exponent $m$ and the temperature dependence by an Arrhénius factor with a stress- independent activation energy. The expression of the stress dependence of dislocation velocity is a persistent problem (see part I). The classical theory of thermally activated processes uses rather a stress dependent (activation volume) activation enthalpy which couple temperature and stress dependences. Applying this formalism to semiconducting materials in order to determine activation enthalpy through the integration of activation volumes gives somewhat confusing results : a fair agreement was found in Si between the activation enthalpy and the activation energy of dislocation velocity but in III-V compounds the analysis of macroscopic data yielded $\Delta G$ values much higher than $Q$ derived from velocity measurements. This might be due to a too large variation of the pre-factor, although the multiplication of dislocations is in principle reduced by prestraining, or to experimental errors in the determination of activation volumes, or last by the failure of the implicit assumption that the stress dependence of dislocation mobility stems from the stress dependence of the activation energy ! One must be extremely cautious when attributing to dislocation mobility, activation energies or activation volumes derived from macroscopic experiments.

v) A present trend in experiments is towards still lower temperatures where plasticity can start under very high stresses provided that britle failure is prevented by a hydrostatic pressure. Such confinement is realized locally under a Vickers indenter for example, but the drawback of the easy-to-do microhardness experiments is a very complex situation with a plastic zone composed of many interacting slip systems and superimposed cracks, which makes difficult the relationship between microhardness data and dislocation mobility or yield stresses.

More interesting are deformation tests under confining pressure which can be conducted very similarly to classical higher temperature ex- 
periments. Very important is to verify the existence and the magnitude of special environment effects that could be due to metallic jacketing for example.

With these reservations in mind, it seems that low temperature plasticity cannot result from a simple extrapolation of the well known intermediate temperature phenomena but is qualitatively different. A possible reason is the possibility of independently moving Shockley partial dislocations but other features, specific to semiconductors, such as the deep electronic energy levels introduced by dislocations, should be considered. Clearly also low temperature plasticity cannot be explained in terms of dislocation velocities measured at much lower stresses. There is a need to extend velocity measurements at high stresses.

vi) The possibility to freeze-in dislocation structures by cooling down in the stress-applied state make semiconductors very attractive materials for a quantitative investigation of dislocation substructures by conventional TEM. Especially at sufficiently low temperatures, mobile dislocations can be distinguished from trapped ones by their crystallographic orientations and local stresses may be derived from the curvature of bends between $\langle 110\rangle$ segments. This opportunity has been exploited in $\mathrm{Si}$, but not in III-V compounds where additional experimental difficulties (stability under the electron beam...) appear however possible to overcome.

vii) The influence of doping impurities on the yield stress is rather well explained by the doping effect on dislocation velocities when conditions of deformation (temperature and strain rates) and impurity concentrations are such that metallurgical effects like segregation, solid solution hardening... are negligible, which is usually the case at moderately low temperature, thanks to the low diffusivity of dopants in SC.

viii) The influence of non doping impurities like oxygen in $\mathrm{Si}$ or isovalent impurities in III-V compounds (e.g. In in GaAs) is more complex and depend on the state of impurities in the sample. Usually the velocity itself is not affected above some critical stress below which dislocations are stopped. One has to distinguish between an immobilization stress for moving dislocations and a starting stress required to move existing dislocations or for source operation. This starting stress is critical in the yield region and depends on the concentration and occasional annealing prior to deformation. Consequently yield stresses depend on the strain rate, the state of the surface (mechanical damage provides dislocation sources)... At not too high temperature non doping impurities usually have a hardening effect but as soon as precipitation occurs a softening can be observed due to the increased density of dislocation sources.

ix) In III-V compounds, there is a need for high temperature data in order to optimize the crystal pulling conditions to avoid dislocations in devices. Such high temperature tests must be done under encapsulation to prevent surface decomposition, This would give direct indications of the mechanical behaviour in pulling conditions but raise the question of a possible environment effect.

x) More fundamental insights into dislocation glide and climb mechanisms could also be obtained by varying the partial pressure of one of the components of CSC during deformation tests as investigated in oxides [102].

\section{References}

[1] George, A., Rabier, J., Revue Phys. Appl. (1987).

[2] Siethoff, H., Schröter, W., Philos. Mag. A 37 (1978) 711.

[3] Brion, H. G., Siethoff, H., Schröter, W., Philos. Mag. A 43 (1983) 1505.

[4] Siethoff, H., SCHRÖter, W., Z. Metallkd 75 (1984) 475

[5] SCHRÖter, W., Siethoff, H., Z. Metallkd 75 (1984) 482.

[6] Alexander, H., HaAsen, P., Solid State Phys. 22 (1968) 26.

[7] OMri, M., Thèse de $3^{\text {c }}$ Cycle, Nancy 1981 ;

Omri, M., Tete, C., Michel, J. P., George, A., Philos. Mag. A 55 (1987) 601.

[8] Oueldennaoua, A., Michel, J. P., George, A., in Dislocations in Solids, Suzuki, Ninomiya, Sumino, Takeuchi eds (University of Tokyo Press) 1985, p. 421.
[9] Gottschalk, H., Patzer, G., Alexander, H., Phys. Status Solidi(a) 45 (1978) 207.

[10] Michel, J. P., OMri, M., Oueldennaoua, A., GeORGE, A., Scr. Metall. 16 (1982) 677.

[11] Omri, M., Michel, J. P., Tete, C., George, A., in Strength of Metals and Alloys ICSMA-7, Mc Queen et al. Eds (Pergamon Press) 2 (1985) p. 75.

[12] Kojima, K. I., Sumino, K., Cryst. Latt. Defects 2 (1971) 147.

[13] Brion, H. G., HaAsen, P., Philos. Mag. A 51 (1985) 879.

[14] Escaig, B., J. Physique 29 (1968) 225.

[15] Mecking, H., in Work hardening in Tension and Fatigue Thomson, A. W., ed. (TMS-AIME) 1977, p. 67

[16] Siethoff, H., Philos. Mag. A 47 (1983) 657.

[17] Bonneville, J., EsCaig, B., Acta Metall. 27 (1979) 1477. 
[18] Bonneville, J., Thèse, Lausanne (1985).

[19] Michel, J. P., Allem, R., George, A., Proc. 7th Int. Conf. on the Strength of Metals and Alloys (ICSMA 7) 1 (1985) 69.

[20] George, A., Escaravage, C., Schröter, W., Champier, G., Cryst. Latt. Defects 4 (1973) 29.

[21] George, A., Champier, G., Scr. Metall. 14 (1980) 399.

[22] Möller, H. J., Philos. Mag. 37 (1978) 41.

[23] Möller, H. J., Ewaldt, H., HaAsen, P., Phys. Status Solidi(a) 55 (1979) 469.

[24] Hazzledine, P. H., KarnthaleR, H. P., WintNER, E., Philos. Mag. 32 (1975) 81.

[25] Johnston, W. G., Gilman, J. J., J. Appl. Phys. 30 (1959) 129.

[26] Yonenaga, I., Sumino, K., Phys. Status Solidi(a) 50 (1978) 685

[27] Schröter, W., AleXander, H., HAASEN, P., Phys. Status Solidi 7 (1964) 983.

[28] Takeuchi, S., J. Phys. Soc. Jpn 35 (1973) 188.

[29] TAKeUCHI, S., Scr. Metall. 7 (1973) 831.

[30] Suezawa, M., Sumino, K., Yonenaga, I., Phys. Status Solidi(a) 51 (1979) 217.

[31] BASINSKI, S. J., BASINSKI, Z. S., in Dislocations in Solids F. R. N. Nabarro ed. (North-Holland, Amsterdam) 4 (1979) 261.

[32] Oueldennaoua, A., Michel, J. P., George, A., Inst. Phys. Conf. Ser. 67 (1983) 33 ;

Oueldennaoua, A., Thèse de $3^{\mathrm{e}}$ Cycle, Nancy (1983).

[33] Allem, R., Thèse de Docteur-Ingénieur, Nancy (1986).

[34] Sсноеск, G., Phys. Status Solidi 8 (1965) 499.

[35] Kocks, U. F., Argon, A. S., Ashby, M. F., Progr. Mater. Sci. 19 (1975).

[36] SureK, T., Luton, M. J., Jonas, J. J., Philos. Mag. 27 (1973) 425.

[37] Burenkov, Yu. A., Nikanorov, S. P., Sov. Phys. Solid State 26 (1984) 1940.

[38] Guiu, F., Pratt, P. L., Phys. Status Solidi 6 (1964) 111.

[39] Gottschalk, H., J. Physique colloq. 44 (1983) C4$69, \mathrm{C} 4-475$

[40] Messerschmidt, U., ApPel, F., Schmid, H., Philos. Mag. A 51 (1985) 781.

[41] Nye, J. F., Acta Metall. 1 (1953) 153.

[42] Shimizu, H., Sumino, K., Philos. Mag. 32 (1975) 123.

[43] Sumino, K., Shimizu, H., Philos. Mag. 32 (1975) 143.

[44] Fnaiech, M., Reynaud, F., Couret, A., CailLARD, D., Philos. Mag. A 55 (1987) 405.

[45] Di Persio, J., Kesteloot, R., J. Physique Colloq. 44 (1983) C4-469.

[46] Steinhardt, H., HaAsen, P., Phys. Status Solidi(a) 49 (1978) 93.

[47] KaRmoudA, M., Thèse de $3^{\mathrm{e}}$ cycle, Lille (1984).

[48] GALl, P., Thèse, INSA Toulouse (1985).

[49] Astie, P., Couderc, J. J., Chomel, P., Quelard, D., Duseaux, M., Phys. Status Solidi(a) 96 (1986) 225.

[50] BoIvin, P., RABIER, J., unpublished results.
[51] George, A., Jacoues, A., Coquille, R., Inst Phys. Conf. Ser. 76 (1985) 439.

[52] Kubin, L. P., Philos. Mag. 30 (1974) 705.

[53] LOUCHET, F., in Dislocations et Déformation Plastique (les Editions de Physique, Paris 1980) p. 149.

[54] OMRI, M., (1986) unpublished results.

[55] Siethoff, H., Acta Metall. 17 (1969) 793 ; Phys. Status Solidi. 40 (1970) 153.

[56] Brion, H. G., HaAsen, P., Siethoff, H., Acta Metall. 19 (1971) 283.

[57] Bowen, D. K., TAylor, G., Acta Metall. 25 (1977) 417.

[58] Demenet, J. L., Desoyer, J. C., Rabier, J., VeYsSIERE, P., Scr. Metall. 18 (1984) 41.

[59] Sazhin, N. P., Mil'Vidskit, M. G., Osvenskit, V. B., Stolyarov, O. G., Sov. Phys. Solid State 8 (1966) 1223.

[60] Laister, D., Jenkins, G. M., J. Mat. Sci. 8 (1973) 1218.

[61] Swaminathan, V., Copley, J. M., J. Amer. Ceram. Soc. 58 (1975) 482.

[62] Eremenko, V. G., Nikitenko, V. I., Phys. Status Solidi(a) 14 (1972) 317.

[63] Pirouz, P., Chaim, R., Samuels, J., Proc. 5th Int. Symp. Structure and Properties of Dislocations in Semiconductors Moscou (1986) to be published.

[64] Hill, M. J., RowCliffe, D. J., J. Mat. Sci. 9 (1974) 1569.

[65] Roberts, S. G., Pirouz, P., Hirsch, P. B., J. Physique 44 (1983) C4-75.

[66] Roberts, S. G., Pirouz, P., Hirsch, P. B., J. Mat. Sci. 20 (1985) 1739.

[67] Yasutake, K., Umeno, M., Kawabe, H., Acta Cryst. A 40 (1984) C334.

[68] Yasutake, K., Stephenson, J. D., Umeno, M., Kawabe, H., Philos. Mag. A 53 (1986) LA1

[69] Vergnol, J. F. M., Grilhe, J. R., J. Physique 45 (1984) 1479.

[70] Korner, A., Martinez-Hernandez, M., George, A., KIrChner, H. O. K., Philos. Mag. A 55 (1987) L-105.

[71] Warren, P. D., Pirouz, P., Roberts, S. G., Philos. Mag. A 50 (1984) L-23.

[72] Lesueur, J., GeOrge, A., unpublished results.

[73] Höche, H. R., Schreiber, J. Phys. Status Solidi(a) 86 (1984) 229.

[74] Hirsch, P. B., Pirouz, P., Roberts, S. G., Warren, P. D., Philos. Mag. B 52 (1985) 759.

[75] Trefilov, V. I., Milman, Yu. V., Sov. Phys. Doklady 8 (1964) 1240.

[76] Gridneva, I. V. Milman, Yu. V., Trefilov, V. I., Phys. Status Solidi(a) 14 (1972) 177.

[77] Gilman, J. J., J. Appl. Phys. 39 (1968) 6086.

[78] Castaing, J., Veyssiere, P., Kubin, L. P., Rabier, J., Philos. Mag. A 44 (1981) 1407.

[79] DEMENET, J. L., unpublished results.

[80] Rabier, J., Veyssiere, P., Demenet, J. L., J. Physique Colloq. 44 (1983) C4-243.

[81] Demenet, J. L., Rabier, J., Garem, H., Inst. Phys. Conf. Ser., in the press.

[82] Küsters, K. H., Alexander, H., Physica 116B (1983) 594 
[83] Veyssiere, P., Rabier, J., Dejmenet, J. L., CasTAING, J., in Deformation of Ceramic Materials II (Plenum Press) R. E. Tressler and R. C. Bradt eds, 1984, p. 37.

[84] Wessel, K., Alexander, H., Philos. Mag. 35 (1977) 1523.

[85] RAbier, J., Garem, H., DEMEnet, J. - L.; Veyssiere, P., Philos. Mag. A 51 (1985) L-67.

[86] BoIVIN, P., RABIER, J., unpublished results.

[87] RABIER, J., GAREM, H., in Materials under extreme conditions M.R.S. (Les Editions de Physique) H. Ahlborn, H. Frederikson, E. Lüscher eds, 1985, p. 177.

[88] Lefebvre, A., Francois, P., di Persio, J., J. Physique Lett. 46 (1985) L1023.

[89] Veyssiere, P., RABier, J., JAulin, H., Demenet, J. L., Castaing, J., Revue Phys. Appl. 20 (1985) 805.

[90] PoIRIER, J. P., Creep of crystals (Cambridge University Press) 1985 , p. 145

[91] Porowski, S., Trzeciakowski, W., Helv. Phys. Acta 56 (1983) 331.
[92] Grazhulis, V. A., Kveder, V. V., Mukhina, V. Yu., Phys. Status Solidi(a) 43 (1977) 407.

[93] Ono, H., Sumino, K., Jpn. J. Appl. Phys. 19 (1980) L629.

[94] Castaing, J., Broniatowski, A., Rabier, J., VeYsSIERE, P., Defects in semiconductors, L. C. Kimerling and J. M. Parsey eds (the Metall. Soc. of AIME) p. 453.

[95] Yonenaga, I., Sumino, K., Jpn. J. Appl. Phys. 21 (1982) 47

[96] Yonenaga, I., Sumino, K., Hoshi, K., J. Appl. Phys. 54 (1983) 5016.

[97] Patel, J. R., Discuss. Faraday Soc. 38 (1964) 201.

[98] Sumino, K., Yonenaga, I., Imai, M., Abe, T., J. Appl. Phys. 54 (1983) 5016.

[99] DJemel, A., Castaing, J., Europhys. Lett. 2 (1986) 611.

[100] Tabache, M. G., Bourret, E. D., Elliot, A. G., Appl. Phys. Lett. 49 (1986) 289.

[101] Estrin, Y., Kubin, L. P., Acta Metall. 34 (1986) 2455.

[102] Bretheau, T., Castaing, J., Rabier, J., VeySSIERE, P., Adv. Phys. 28 (1979) 829. 